\title{
An Activity-Generating Theory of Regulation
}

\section{Citation}

Schwartzstein, Joshua, and Andrei Shleifer. 2013. "An Activity-Generating Theory of Regulation." The Journal of Law and Economics 56 (1) (February): 1-38. doi:10.1086/666959.

\section{Published Version}

10.1086/666959

\section{Permanent link}

http://nrs.harvard.edu/urn-3:HUL.InstRepos:27814564

\section{Terms of Use}

This article was downloaded from Harvard University's DASH repository, and is made available under the terms and conditions applicable to Other Posted Material, as set forth at http:// nrs.harvard.edu/urn-3:HUL.InstRepos:dash.current.terms-of-use\#LAA

\section{Share Your Story}

The Harvard community has made this article openly available.

Please share how this access benefits you. Submit a story.

Accessibility 


\title{
An Activity-Generating Theory of Regulation
}

\author{
Joshua Schwartzstein Dartmouth College \\ Andrei Shleifer Harvard University
}

\begin{abstract}
We propose an activity-generating theory of regulation. When courts make errors, tort litigation becomes unpredictable and as such imposes risk on firms, thereby discouraging entry, innovation, and other socially desirable activity. When social returns to activity are higher than private returns, it may pay the society to generate some information ex ante about how risky firms are and to impose safety standards based on that information. In some situations, compliance with such standards should entirely preempt tort liability; in others, it should merely reduce penalties. By reducing litigation risk, this type of regulation can raise welfare.
\end{abstract}

\section{Introduction}

According to the standard law and economics analysis (Coase 1960), private contracting and optimal tort rules leave very little room for efficient government regulation. Yet regulation is common and growing over a broad range of activities and, if anything, is more ubiquitous in richer, more democratic societies. In light of the Coasean logic, how can this be the case?

In this paper, we present a new case for efficient regulation, based on the idea that, compared to pure litigation, regulation alone or in combination with litigation can encourage socially desirable economic activity. Our theory is based on two fundamental assumptions. First, we assume that courts make errors that impose risk on firms. The litigation risk manifests itself in lower levels of economic activity such as the reluctance of some firms to enter. The recognition that courts make errors, particularly in the assessment of complex risks and damages, and that such errors affect firm decisions is quite standard in law and

We thank Gary Becker, Georgy Egorov, Edward Glaeser, Oliver Hart, Louis Kaplow, Richard Posner, Ricky Revesz, Jesse Shapiro, Steven Shavell, Lucy White, an anonymous referee, and an editor for helpful comments. Schwartzstein acknowledges financial support from a National Bureau of Economic Research predoctoral fellowship in health and aging.

[Journal of Law and Economics, vol. 56 (February 2013)]

(C) 2013 by The University of Chicago. All rights reserved. 0022-2186/2013/5601-0001\$10.00 
economics (for example, Calabresi 1970; Calfee and Craswell 1984; Craswell and Calfee 1986; Kolstad, Ulen, and Johnson 1990; Kaplow and Shavell 1996).

Second, and perhaps more original in the discussion of regulation, we assume that economic activity is quite socially desirable and, in particular, that the social returns to such activity are higher than private returns. This assumption may cover situations in which innovators, such as pharmaceutical companies, earn returns that are lower than the social value of new drugs and may be deterred from introducing new products by litigation risk (Mankiw and Whinston 1986). It may also cover activities such as nuclear power generation, which earns social returns such as energy independence not captured by the producer. But we take a much broader view that social returns to productive activity are higher than private returns whenever the economy is not at full employment and job creation relieves the state of its social obligations. Scholars in public finance estimate that raising $\$ 1$ of tax revenue entails a marginal deadweight cost of about $\$ .25$ (see, for example, Chetty 2011). This means that whenever a firm replaces $\$ 20,000$ of welfare or unemployment benefits with wages to a new employee, $\$ 5,000$ in social gains is created but not captured by this firm.

Under these two assumptions, government regulation either by itself or in combination with litigation can encourage economic activity by reducing the litigation risk facing firms and thus can be more efficient than litigation alone. Our analysis provides an analytical foundation for the commonly made argument that there is room for regulation when litigation drives firms out of business or discourages innovation (Viscusi 1991; Viscusi and Moore 1993). ${ }^{1}$

We develop these arguments in a fairly standard model of public policies used to create incentives for firms to take precautions. In this model, absent court errors, a negligence regime with appropriate penalties creates incentives for efficient precautions and activity. When courts make errors, however, incentives for precautions and activity become distorted. In this framework, we think of regulators as first screening firms (or products) as risky or not and then mandating precautions for firms deemed to be risky, a view of regulation similar to Shavell (1984a, 1984b). When such regulation is combined with litigation, courts can take compliance with regulatory standards into account. We assume that regulators, like courts, make errors, although we consider the possibility that, as specialists, they are less prone to error than courts (Landis 1938). With regulatory errors, it is sometimes efficient for misclassified firms to ignore regulatory mandates, and the enforcement schemes we consider allow firms to do so. With this caveat, our model is similar to the standard command-and-control regulation

\footnotetext{
${ }^{1}$ According to Calabresi (1970, p. 270), "Too large a fine or criminal penalty in an area where errors are likely may, as we have already seen, result in individuals abstaining from conduct we do not wish to affect, such as driving in general, for fear that if they drive at all they may occasionally be incorrectly condemned and penalized."
} 
contingent on the information collected by the regulator. ${ }^{2}$ As an example, we can think of the regulator as classifying a power plant design as safe or less safe, and calling for additional safety measures for the latter, or a new drug as safe or less safe, and calling for warning labels for the latter. Or we can think of the regulator mandating additional pollution controls such as scrubbers or pollution filters for some but not other plants, depending on their technology. We derive optimal policies under litigation alone, regulation alone, and the combination of the two and examine the conditions under which regulation improves welfare. We thus make precise the argument for activity-generating regulation.

In our framework, compliance with regulatory standards need not automatically insulate firms from subsequent tort liability completely, although it would generally reduce the optimal penalties. At the same time, our model enables us to analyze the preemption doctrine, which holds that compliance with regulatory requirements should provide safe harbor against litigation risks. In particular, we suppose that, along with granting the regulator authority to classify firms and recommend precautions, the legislature can mandate that compliance with regulations insulates a firm from subsequent tort liability even if an accident occurs. When would such a legislative mandate be efficient? The U.S. Supreme Court has struggled with this doctrine in the area of medical safety, deciding that Food and Drug Administration (FDA) approval should preempt tort liability for medical devices (Riegel v. Medtronic, 552 U.S. 312 [2008]) but not for drugs (Wyeth v. Levine, 555 U.S. 555 [2009]). The question of preemption in the United States raises complex issues of division of powers between branches of government and between the federal government and the states (Schwartz 2000; Kessler and Vladeck 2008; Curfman, Morrissey, and Drazen 2008; Glanz and Annas 2008; Philipson, Sun, and Goldman 2009). Here we ask the much simpler question of efficiency: when should the legislature efficiently mandate preemption for firms that comply with regulations? Since our model derives efficient rules for the control of harmful risks, it allows us to address this question.

We show that when social benefits from activity are sufficiently high relative to the harm from insufficient precautions (to be precise, on net even the activity of negligent firms is socially desirable), then the optimal rule is complete safeharbor regulation, whereby a firm that satisfies the regulatory standard is exempt from damages when an accident occurs. Regulatory compliance preempts tort liability. In contrast, if the social benefits of activity are not so high, then the optimal policy should allow for negligence claims even against firms that comply with regulations, although the magnitude of damage awards is lower for such firms. Regulatory compliance does not preempt liability. Under our theory, the

\footnotetext{
${ }^{2}$ In fact, we also examine the case of pure command-and-control regulation, in which even the firms for which it is not efficient to follow regulatory mandates are forced to do so (or, equivalently, penalties for not following the mandates are sufficiently large). We show that such regulation is less efficient than the optimal regulatory scheme we consider, in which a misclassified firm can choose to ignore regulatory mandates. Nonetheless, even the suboptimal regulatory scheme can be superior to litigation.
} 
preemption doctrine as applied to private common-law tort actions might be efficient in governing the safety of some pharmaceuticals with very high social benefits but not that of automobiles or airplanes.

To illustrate how the theory works, consider a simple example. Suppose that a company is considering the construction of a nuclear power plant and that the design can be either relatively safe or relatively unsafe as captured by the likelihood of an accident allowing radiation to escape. (For example, it could be the same design in seismologically different locations.) In the latter case, it is first-best efficient for the company to invest in additional safety precautions; in the former, it is not. Suppose that the social benefits of constructing the plant exceed the private benefits (for example, national interest in energy independence, reduced pollution), but the plant cannot be subsidized. Nonetheless, if unsafe designs can be perfectly identified, it is conditionally efficient to incentivize companies with such designs to take precautions: the social loss from some such companies avoiding costs by not building is outweighed by the gain from incentivizing those that enter to take precautions. Suppose finally that if an accident occurs and radiation escapes, the court determines without error whether precautions had been taken but possibly with error whether the design is unsafe and therefore precautions should have been taken.

In this example, without court errors, a negligence rule can achieve efficient precautions by all firms and conditionally efficient entry given the constraint that firms cannot be subsidized. With court errors, however, a negligence regime has the unintended consequence that firms with safe designs also face the risk of being held liable after an accident for failure to take precautions. As a consequence, some firms may (inefficiently) choose not to operate. Regulators have the ability to encourage entry by making an ex ante determination of whether a design is safe or unsafe and effectively limit liability costs for companies with designs determined to be safe, even if regulators also make errors. The benefit of introducing such regulation depends on the degree to which it is targeted: it limits liability costs for and only for companies with safe designs. It also depends on the degree to which entry needs to be encouraged, an increasing function of the shortfall of the private benefits of constructing the plant from the social ones.

If introducing such regulation is welfare enhancing, should a regulatory finding that a design is safe eliminate future liability under negligence or merely reduce the damages? If regulators never mistakenly classify an unsafe design as safe, then it is unambiguous that liability costs should be eliminated. On the other hand, if regulators make mistakes, then some companies with unsafe designs are affected by the regulation. In this case, the answer depends on whether the construction of nuclear plants with unsafe designs is socially beneficial even when precautions are not taken. If yes, then liability costs should still be eliminated. If no, then it is desirable to set low damages (expected damages < cost of precautions) that deter the construction of some plants with unsafe designs without affecting the construction of plants with safe designs. 
Our theory of regulation does not merely make the point that collection of more information by law enforcers can enhance efficiency. Similar points have already been made by, for example, Craswell and Calfee (1986) and Kolstad, Ulen, and Johnson (1990). Rather, the previous literature has focused on how regulators can create incentives for firms to take more efficient precautions when a pure-liability regime results in too few. In our model, courts can implement first-best precautions even without additional information but may not be able to encourage the correct level of activity. Our principal innovation is to analyze a model with socially valuable activity, to identify conditions under which a pureliability system results in too little activity, to analyze when and how the ex ante public collection of information can improve welfare through promoting activity, and to use the model to examine when preemption is efficient. We show that the activity-generating case for regulation relies both on courts errors and on the existence of positive externalities to firm activity.

Our paper is related to several strands of research in law and economics. Becker (1968), Calabresi (1970), Posner (1972, 1973), and Spence (1977) initiate the research on alternative methods of controlling harmful behavior and, in particular, on comparing regulation and litigation. Shavell (1980) and Polinsky (1980) consider activity levels in assessing the optimal liability rules but not regulation. Immordino, Pagano, and Polo (2011) analyze the performance of different methods of controlling harmful externalities when innovation may be discouraged. Craswell and Calfee (1986), Png (1986), Kolstad, Ulen, and Johnson (1990), and Polinsky and Shavell (2000) examine the implications of errors in enforcement for optimal fines. Kaplow and Shavell (1996) provide a general analysis of the effects of accuracy in the assessment of damages. Gennaioli and Shleifer (2008) endogenize court errors as the result of judicial policy preferences. Essentially, the assumption of errors in law enforcement implies that rules governing the behavior of safe firms also affect unsafe firms and vice versa.

There is also some research on when regulation might be preferred to litigation. One previously examined case for regulation is based on the judgment-proof problem. If, with liability, damages might be so high that the liable firm or individual would be unable to pay them, regulation might be optimal (Shavell 1984a, 1984b, 1993; Summers 1983). The judgment-proof problem is particularly applicable to small firms with limited resources. However, it is often the large corporations, with considerable resources as well as access to insurance, that are being regulated. Another economic argument for regulation includes the greater expertise of regulators than of judges (Landis 1938; Glaeser, Johnson, and Shleifer 2001); our model allows some results bearing on the question of expertise. Still another idea is that pure-liability regimes are more vulnerable to persuasion and bribery because they entail greater ex post fines (Becker and Stigler 1974; Glaeser and Shleifer 2003). In this paper, we abstract from the judgment-proof problem or the incentives of law enforcers. Instead, our paper examines the case for regulation under three substantive assumptions: that the structure of penalties 
affects not just precautions but the level of activity, that private returns to activity are lower than social returns, and that both courts and regulators make errors.

Section 2 presents the basic model of litigation and regulation. Section 3 considers outcomes and social welfare under the efficient-liability regime implemented by courts alone and demonstrates that the case for activity-generating regulation rests on private returns to activity being lower than social returns. Section 4 asks when replacing litigation with pure regulation improves welfare. Section 5 describes the circumstances under which adding regulation to litigation improves resource allocation, characterizes efficient combined regimes, and addresses the question of optimality of preemption. Section 6 briefly considers firm behavior under two important but not optimal regimes: strict liability and negligence when damages are restricted to equal harm. Section 7 concludes.

\section{Model}

\subsection{Setup}

A firm decides whether or not to engage in an activity, $y \in\{0,1\}$ (whether to bring a drug to market or to build a nuclear power plant). If it does not engage in activity $(y=0)$, it receives a payoff of zero. If it engages in activity, it receives private gross payoff of $b-e$, where $b>0$ is the gross social return to firm activity, which is constant across firms, and $e \sim U[0, \bar{e}](\bar{e}<b)$ is a firmspecific parameter that measures the shortfall of the private gross benefit of an activity from the social one. In most models of law enforcement, $e=0$ for all firms $(\bar{e}=0)$, but here we focus on the more general case. ${ }^{3}$

We make the fairly standard assumption that firms cannot be subsidized, which is important given that firms may not capture the full social benefit from their activity. ${ }^{4}$

Assumption 0. Transfers to firms are not possible.

If a firm engages in the activity, it also decides on its level of precautions $p \in\{0,1\}$ (whether to warn physicians of a potential side effect of taking a drug or to make additional safety investments). Not taking precautions $(p=0)$ is costless. Taking precautions $(p=1)$ costs the firm $c$ and may decrease the

\footnotetext{
${ }^{3}$ In our model, firms vary in their ability to appropriate social benefits. Another interpretation is that there is a single, representative, firm but that courts and regulators are uncertain about that firm's ability to appropriate social benefits. We obtain similar but messier results under the alternative assumption that firms vary in the social returns from their activity $(b)$ and that private returns equal $\alpha b(0 \leq \alpha \leq 1)$.

${ }^{4} \mathrm{~A}$ more general model could allow for subsidies conditional on a firm engaging in activity but specify that raising $\$ 1$ to subsidize firms costs society $(1+\lambda)$, where $\lambda>0$ represents the exogenously given shadow cost of public funds (as in Laffont and Tirole [1993]). We do not believe that generalizing the model in this manner would lead to qualitatively different insights, but it would complicate the analysis.
} 
probability of an accident. The accident imposes a social cost $h$, which is assumed to be the same for all accidents. ${ }^{5}$

The payoff to the firm if it engages in activity is

$$
(b-e-c p-L) \text {, }
$$

where $L$ (a function we will derive) stands for expected liability costs given the firm's type and its level of precautions. The firm's problem is to choose its level of precautions $p \in\{0,1\}$ and activity $y \in\{0,1\}$ to maximize ${ }^{6}$

$$
(b-e-c p-L) y \text {. }
$$

The social payoff that results from a given firm choosing precautions $p$ and activity $y$ equals

$$
(b-c p-H) y \text {, }
$$

where $H$ stands for expected harm given the firm's type and level of precautions.

For each firm, activity is a $\{0,1\}$ decision. The activity level of firms that face expected costs $c p+L$ if they choose to operate equals the count of the number of firms for which this cost is less than the private benefit of activity, $b-e$. Equivalently, the activity level equals the number of firms for which $e \leq b-$ $c p-L$. By the assumption that $e \sim U[0, \bar{e}]$, this level equals

$$
\min \left\{\frac{b-c p-L}{\bar{e}}, 1\right\} .
$$

Firms differ in whether or not taking precautions is efficient. Denote this aspect of the firm's type $\theta$, which is independent of $e$. Fraction $\alpha<1$ of firms are safe: $\theta=S$. For a safe firm, the probability of an accident is independent of the level of precautions and equals $\pi_{\mathrm{S}}(p) \equiv \pi_{\mathrm{S}}>0$. Hence it is socially inefficient for a safe firm to take precautions.

Fraction $1-\alpha<1$ of firms are unsafe: $\theta=U$. For an unsafe firm, the probability of an accident depends on whether or not it takes precautions. If it fails to take precautions, the probability of an accident is $\pi_{\mathrm{U}}(0) \equiv \pi_{\mathrm{U}}>\pi_{\mathrm{S}}$. If it takes precautions, the probability of an accident is $\pi_{\mathrm{U}}(1) \equiv \pi_{\mathrm{U}}^{L}<\pi_{\mathrm{U}}$.

We assume that it is socially efficient for unsafe firms to take precautions conditional on engaging in activity:

\footnotetext{
${ }^{5}$ Our model departs from some others in the literature (for example, Kolstad, Ulen, and Johnson 1990), by treating precautions as binary rather than continous. Using continuous rather than discrete precautions affects the precise predictions of our model (for example, the exact design of optimal regimes) but does not alter the intuitions we identify.

${ }^{6}$ When firm activity is interpreted as manufacturing a marketable product, we are implicitly assuming that customers do not take accident risks into account. This could be because harm falls on someone other than the customer (Shavell 1980), for example, if production causes pollution. Alternatively, the customer could fail to appreciate the risks associated with buying a product. When harm falls on the consumer, it is well known that consumer misperceptions are often a necessary condition for welfare-improving liability rules or regulation in the first place (for example, Spence 1977; Shavell 1980). Otherwise, market forces alone would create incentives for firms to take proper precautions.
} 
Assumption 1. $\left(\pi_{\mathrm{U}}-\pi_{\mathrm{U}}^{L}\right) h>c$.

We also assume that unsafe firms generate positive social returns to activity so long as they take precautions (guaranteeing that it is never optimal to shut down a firm) but do not restrict whether they generate positive returns if they fail to take precautions. In addition, we assume that safe firms generate positive social returns to activity:

Assumption 2. $b>\max \left\{c+\pi_{\mathrm{U}}^{L} h, \pi_{\mathrm{S}} h\right\}$.

\subsection{First-Best Condition}

Before introducing courts and regulators, briefly consider the market failure. To solve for the first-best outcome, maximize social payoff equation (3) with respect to activity $y$ and precautions $p$ for each firm. Under our assumptions, it is clear that, in the first-best outcome, safe firms do not take precautions, unsafe firms take precautions, and all firms engage in activity. Welfare in the first-best outcome is

$$
W^{\mathrm{FB}}=\alpha\left(b-\pi_{\mathrm{S}} h\right)+(1-\alpha)\left(b-c-\pi_{\mathrm{U}}^{L} h\right) .
$$

\subsection{Laissez-Faire}

In the absence of liability rules, each firm maximizes

$$
(b-e-c p) y,
$$

since each firm faces zero liability costs $(L=0)$. As a consequence, all firms engage in activity (since $\bar{e}<b$ by assumption), and no firm takes precautions since $c>0$. Welfare under laissez-faire is

$$
W^{\mathrm{LF}}=\alpha\left(b-\pi_{\mathrm{S}} h\right)+(1-\alpha)\left(b-\pi_{\mathrm{U}} h\right) .
$$

The difference in welfare between the first-best outcome and laissez-faire is given by $W^{\mathrm{FB}}-W^{\mathrm{LF}}=(1-\alpha)\left[\left(\pi_{\mathrm{U}}-\pi_{\mathrm{U}}^{L}\right) h-c\right]$, which is the social loss from unsafe firms taking inefficiently few precautions (this loss is positive by assumption 1). Courts and regulators can help bring outcomes more in line with the first-best outcome.

\subsection{Courts}

A case is brought against a firm if and only if it causes an accident. ${ }^{7}$ If a case is brought, the court can observe whether the firm took precautions as well as a noisy signal $\sigma_{\mathrm{J}}$ of firm safety $\theta \in\{\mathrm{S}, \mathrm{U}\}$, where

$$
\operatorname{Pr}\left[\sigma_{\mathrm{J}}=\hat{\mathrm{S}} \mid \theta=\mathrm{U}, e=e^{\prime}\right]=\varepsilon_{\mathrm{S} \mid \mathrm{U}}
$$

and

\footnotetext{
${ }^{7}$ Setting the probability of a lawsuit equal to one is without loss of generality since damages are not capped. For the same reason, we do not need to consider court injunctions to activity.
} 


$$
\operatorname{Pr}\left[\sigma_{\mathrm{J}}=\hat{\mathrm{U}} \mid \theta=\mathrm{S}, e=e^{\prime}\right]=\varepsilon_{\mathrm{U} \mid \mathrm{S}}
$$

for all $e^{\prime} \in[0, \bar{e}]$. Here $\varepsilon_{\mathrm{S} \mid \mathrm{U}}$ and $\varepsilon_{\mathrm{U} \mid \mathrm{S}}$ represent court errors in determining whether a firm is safe. We assume that errors cannot be too large or, equivalently, that court signals are informative:

Assumption 3. $0 \leq \varepsilon_{\mathrm{S} \mid \mathrm{U}} \leq \frac{1}{2} ; 0 \leq \varepsilon_{\mathrm{U} \mid \mathrm{S}} \leq \frac{1}{2}$.

The court imposes damages $D \geq 0$, where $D$ is a function of whether the firm took precautions, as well as available information regarding firm safety. ${ }^{8}$ While the court verifies the firm's type with error, it is able to perfectly verify whether precautions had been taken (it can verify whether safety investments were made, inspections conducted, or doctors warned).

\subsection{Regulators}

If the enforcement method involves regulators, then prior to a firm's choice of precautions and activity, a regulator generates a public signal $\sigma_{\mathrm{R}}$ which is correlated with firm safety $\theta$, where

$$
\operatorname{Pr}\left[\sigma_{\mathrm{R}}=\hat{\mathrm{S}} \mid \theta=\mathrm{U}, e=e^{\prime}\right]=\delta_{\mathrm{S} \mid \mathrm{U}}
$$

and

$$
\operatorname{Pr}\left[\sigma_{\mathrm{R}}=\hat{\mathrm{U}} \mid \theta=\mathrm{S}, e=e^{\prime}\right]=\delta_{\mathrm{U} \mid \mathrm{S}}
$$

for all $e^{\prime} \in[0, \bar{e}]$. The public signal is interpreted as reflecting the regulator's ex ante determination of whether the firm is unsafe and should take precautions (namely, the firm is determined to be unsafe if and only if $\sigma_{\mathrm{R}}=\hat{U}$ ). Then $\delta_{\mathrm{S} \mid \mathrm{U}}$ and $\delta_{\mathrm{U} \mid \mathrm{S}}$ are regulatory errors in firm classification. We assume that these errors cannot be too large or, equivalently, that the regulatory signals are informative:

Assumption 4. $0 \leq \delta_{\mathrm{S} \mid \mathrm{U}} \leq \frac{1}{2} ; 0 \leq \delta_{\mathrm{U} \mid \mathrm{S}} \leq \frac{1}{2}$.

For simplicity, we assume that regulators and courts observe independent signals conditional on a firm's type:

Assumption 5. $\operatorname{Pr}\left[\sigma_{\mathrm{R}}=r, \sigma_{\mathrm{J}}=j \mid\right.$ firm's type $]=\operatorname{Pr}\left[\sigma_{\mathrm{R}}=r \mid\right.$ firm's type $] \times$ $\operatorname{Pr}\left[\sigma_{\mathrm{J}}=j \mid\right.$ firm's type $]$ for all $r=\hat{\mathrm{S}}$ or $\hat{\mathrm{U}}$ and $j=\hat{\mathrm{S}}$ or $\hat{\mathrm{U}}$.

Regulators investigate whether a firm took precautions and impose a fine $F \geq 0$, where $F$ is a function of the regulatory classification as well as whether

\footnotetext{
${ }^{8}$ Note that we restrict damages to be weakly positive. There are several reasons for imposing this restriction (Emons and Sobel 1991). Perhaps most important, if expected damages were negative for some firms, then they may engage in the activity for no other reason than the possibility of gaining in the case of an accident. Formally, in addition to safe and unsafe firms, suppose there are infinitely many other firms that do not generate value $(b=e=0$ for these firms) but may be mistaken as safe or unsafe with positive probability if they cause an accident. Such firms may inefficiently choose to enter if damages are negative.
} 
the firm took precautions or caused an accident. Our setup nests traditional command-and-control regulation in which the regulator directly controls whether the firm takes precautions, since the regulator has enough flexibility in setting the fine that it can create incentives for all firms to take precautions. By allowing the fine to depend on whether the firm caused an accident (for example, if the regulator investigates only whether the firm took precautions in the event of an accident), our setup also allows for regulation that can more efficiently target unsafe firms by making use of information about whether a firm causes an accident. By allowing the fine to depend on the regulatory classification, for example, if the fine is positive only if the firm is classified as unsafe, our setup also allows for regulation bearing resemblance to performance-based standards (for example, new electric utilities can pollute only some amount of sulfur dioxide per million BTUs of heat input) rather than design standards (for example, they must use scrubbers). The regulatory signal that the firm is unsafe can be interpreted as indicating that a firm has not met a performance standard and must take some action in order to do so. When regulators make errors, the assumption is that they cannot perfectly determine whether a performance standard has been met.

If the enforcement method involves courts together with regulators, the regulatory classification can be considered by the court in setting damages. Summarizing the timing of the model:

Period 0. Each firm learns its true type $(\theta, e)$. If the enforcement method involves courts, the damage award function $D(\cdot) \geq 0$ is announced, where $D=D\left(p, \sigma_{\mathrm{J}}\right)$ if the enforcement method involves only courts and $D=D(p$, $\left.\sigma_{\mathrm{J}}, \sigma_{\mathrm{R}}\right)$ if the method also involves regulators. If the enforcement method involves regulators, the fine schedule $F=F\left(p, \sigma_{\mathrm{R}}, a\right)$ is announced, where $a \in\{0,1\}$ represents whether the firm causes an accident.

Period 1. If the enforcement method involves regulators, then for each firm, the regulator generates a public signal $\sigma_{\mathrm{R}}$ that is correlated with firm safety $\theta$.

Period 2. Each firm decides whether to engage in activity $(y \in\{0,1\})$ and whether to take precautions $(p \in\{0,1\})$.

Period 3. Any uncertainty about whether a firm causes an accident is realized. If a firm causes an accident and the enforcement method involves courts, then the court generates a signal $\sigma_{\mathrm{J}}$ that is correlated with firm safety $\theta$ and imposes damages $D$ in accordance with the previously announced damage award function $D(\cdot)$. If the enforcement method involves regulators, then the regulator imposes a fine $F$ in accordance with the previously announced fine function $F(\cdot)$.

\section{Courts Alone}

We first consider the performance of courts alone $\left(D=D\left(p, \sigma_{\mathrm{J}}\right)\right)$. For any enforcement regime involving only courts (as described by $D\left(p, \sigma_{\mathrm{J}}\right)$ ), each firm chooses its level of precautions and activity to maximize expression (2). Denote 
the maximum level of social welfare achievable by an enforcement regime involving only courts by $W^{\mathrm{C}}$.

\subsection{Special Case: No Positive Externalities to Firm Activity}

Consider the special case in which, before taking harmful externalities into account, firms fully internalize the social surplus generated by their activity: $\bar{e}=0$. In this case, courts alone can implement the first-best outcome. Consider a strict-liability regime with damages equal to harm (namely, a firm pays $h$ whenever it causes an accident). Under this regime, each firm chooses precautions $p$ and activity $y$ to maximize

$$
(b-e-c p-H) y=(b-c p-H) y,
$$

where the equality follows from $0 \leq e \leq \bar{e}=0$ (recall that $H$ stands for expected harm given the firm's type and level of precautions). Since the righthand side of equation (8) is exactly the social payoff that results from a given firm choosing precautions $p$ and activity $y$ (namely, it is equivalent to equation [3]), we have the following proposition:

Proposition 1. With no positive externalities to firm activity $(\bar{e}=0)$, courts alone can implement the first-best outcome through a regime of strict liability with damages equal to harm.

Proposition 1 establishes that, absent positive externalities from firm activity, there is no role for regulation. Having strict liability with damages equal to harm ensures that precautions and activity levels are first best. In particular, generating additional information about firm safety cannot be helpful in this standard scenario. In fact, there is no need to collect any information about firm safety to create incentives for efficient precautions without distorting activity. ${ }^{9}$

However, there may be room for regulation when there are positive externalities to firm activity $(\bar{e}>0)$. To develop a useful necessary condition for when regulation can help in this more general case, we first establish a tighter bound on what is achievable by regimes involving both courts and regulators.

\subsection{General Case}

\subsubsection{Full-Information Benchmark}

In the enforcement regimes we consider, welfare levels cannot be higher than when damages are made directly contingent on whether a firm is safe or unsafe (namely, $D=D(p, \theta)$ ) and are set to maximize social surplus. We use this fullinformation benchmark to assess the performance of alternative enforcement methods.

\footnotetext{
${ }^{9}$ Absent positive externalities, the results of Section 3.2 imply that a properly designed negligence regime can also implement the first-best outcome: court errors do not matter. With limited liability, generating information about firm safety can help create incentives for firms to take efficient precautions (see, for example, Glaeser and Shleifer 2003).
} 
To limit the number of cases considered and to keep the problem interesting, we assume that, absent subsidies, the net effect on social welfare of mandating that unsafe firms take precautions is positive (taking into account the impact on both the likelihood of an accident and activity):

Assumption 6. $\min \{(b-c) / \bar{e}, 1\}\left(b-c-\pi_{\mathrm{U}}^{L} h\right)>b-\pi_{\mathrm{U}} h$.

When assumption 6 does not hold, laissez-faire is necessarily optimal. ${ }^{10}$ When damages can be made contingent on firm safety, it is clear that the damage schedule for unsafe firms should be set to create incentives for these firms to take precautions (by assumption 6) while not exposing these firms to damages when they do take precautions (by assumption 2). ${ }^{11}$ It is also clear that it is (weakly) optimal to never expose safe firms to damages (by assumption 2). Under any damage schedule satisfying these conditions, unsafe firms take precautions and engage in activity so long as $e \leq b-c$, while safe firms do not take precautions and all engage in activity. Welfare equals

$$
W^{\mathrm{FI}}=\alpha\left(b-\pi_{\mathrm{s}} h\right)+(1-\alpha) \min \left\{\frac{b-c}{\bar{e}}, 1\right\}\left(b-c-\pi_{\mathrm{U}}^{L} h\right) .
$$

Comparing this upper bound on welfare with welfare under the first-best outcome, we have

$$
W^{\mathrm{FB}}-W^{\mathrm{FI}}=(1-\alpha)\left(1-\min \left\{\frac{b-c}{\bar{e}}, 1\right\}\right)\left(b-c-\pi_{\mathrm{U}}^{L} h\right),
$$

which is the loss from some unsafe firms choosing not to operate given the costs of precautions (recall that $e \sim U[0, \bar{e}]$ ). If $\bar{e} \leq b-c$, then this loss is zero, which reflects the fact that if positive externalities are sufficiently low, then no loss results from the inability to directly control firm activity (or from the inability to subsidize firms).

In the remainder of the paper, we analyze and compare firm behavior under enforcement regimes implemented by courts alone, regulators alone, or regulators together with courts and consider when adding regulators gets closer to the full-information benchmark. We maintain assumptions 0-6 throughout the paper, except in the statement of proposition 7, where we relax assumption 6 .

\subsubsection{Negligence}

Consider negligence regimes, in which damages are zero whenever a firm takes precautions or is found to be safe. As illustrated in Figure 1, any negligence

${ }^{10}$ One simple condition that implies assumption 6 is $\left(\pi_{\mathrm{U}}-\pi_{\mathrm{U}}^{L}\right) h>2 c$.

${ }^{11}$ For example, the planner could set

$$
D(p, U)= \begin{cases}\frac{c}{\pi_{U}} & \text { if } p=0 \\ 0 & \text { if } p=1\end{cases}
$$




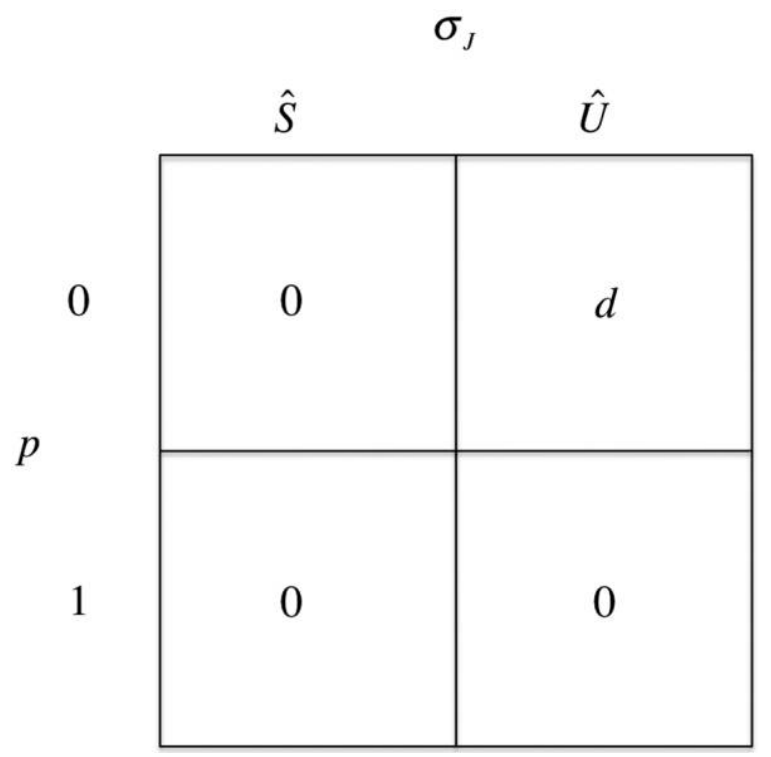

Figure 1. Damages under negligence, where damages are a function of the level of precautions $(p \in\{0,1\})$ and the court's signal $\left(\sigma_{J} \in\{\hat{S}, \hat{U}\}\right)$.

regime can be described by $d \geq 0$, the level of damages a firm must pay in the case of an accident if it is found to have not taken precautions and to be unsafe. Negligence regimes are a subset of all enforcement regimes involving only courts. Denote the maximum level of social welfare achievable by a negligence regime $W^{\mathrm{N}}$, which must lie weakly below the maximum level achievable by courts, namely, $W^{\mathrm{N}} \leq W^{\mathrm{C}}$.

To illustrate, take the drug example. Under negligence, after an accident occurs, a judge or jury decides both whether the drug company did warn and whether it should have warned physicians of a potential side effect. A plaintiff is awarded damages if the court decides (possibly incorrectly) that the drug company should have warned but failed to do so.

Lemma $1 . W^{\mathrm{N}}=W^{\mathrm{C}}$.

By lemma 1 we only need to consider negligence regimes to establish what is achievable through enforcement methods that involve only courts. The intuition for why negligence regimes are optimal is that by using the maximal amount of information regarding a firm's type and whether precautions had been taken, such regimes minimize safe firms' exposure to liability costs (fixing desired behavior on the part of unsafe firms) and eliminate unsafe firms' exposure conditional on taking precautions. We next ask when negligence, and thus courts alone, can implement the full-information benchmark. This outcome can be 
achieved through a negligence regime if and only if it can be achieved when damages are the minimum necessary to create incentives for unsafe firms to take precautions. Label such damages $\bar{d}$, so $\bar{d}$ equates the cost of precautions with the expected liability cost for an unsafe firm if no precautions are taken:

$$
c=\pi_{\mathrm{U}}\left(1-\varepsilon_{\mathrm{S} \mid \mathrm{U}}\right) \bar{d} \Rightarrow \bar{d}=\frac{c}{\left(1-\varepsilon_{\mathrm{S} \mid \mathrm{U}}\right) \pi_{\mathrm{U}}} .
$$

When $d=\bar{d}$, a safe firm optimally chooses not to take precautions since such firms are less likely than unsafe firms to cause an accident and to be found unsafe:

$$
c>\pi_{\mathrm{S}} \varepsilon_{\mathrm{U} \mid \mathrm{S}} \bar{d}
$$

where the right-hand term is the expected liability cost for a safe firm if no precautions are taken.

Now we consider firm activity when $d=\bar{d}$. Because damages $\bar{d}$ are such that unsafe firms take precautions, these firms are not exposed to liability costs. As a result, a given unsafe firm engages in activity if

$$
b-e-c \geq 0 \text {. }
$$

Inequality (12) implies that the activity level of unsafe firms is

$$
\min \left\{\frac{b-c}{\bar{e}}, 1\right\}
$$

which is the full-information benchmark level.

Because damages $\bar{d}$ are such that safe firms do not take precautions, they are exposed to liability costs due to court errors. As a result, a given safe firm engages in activity if

$$
b-e-\pi_{\mathrm{S}} \varepsilon_{\mathrm{U} \mid \mathrm{s}} \bar{d} \geq 0 .
$$

Inequality (14) implies that the activity level of safe firms is

$$
\min \left\{\frac{b-\pi_{\mathrm{S}} \varepsilon_{\mathrm{U} \mid \mathrm{s}} \bar{d}}{\bar{e}}, 1\right\},
$$

which is the full-information benchmark level if and only if

$$
\bar{e} \leq b-\pi_{\mathrm{S}} \varepsilon_{\mathrm{U} \mid \mathrm{s}} \bar{d} .
$$

We have proved the following:

Proposition 2. Courts alone can implement the full-information benchmark if and only if

$$
\bar{e} \leq b-\pi_{\mathrm{S}} \varepsilon_{\mathrm{U} \mid \mathrm{S}} \bar{d} \equiv \tilde{e}
$$

Proposition 2 establishes a necessary and sufficient condition for courts alone to implement the full-information benchmark and there to be no room for 
regulation. There is no room for regulation when inequality (17) holds, which is the condition for it to be possible for a negligence regime to create incentives for unsafe firms to take precautions without deterring safe firms from participating in the market. In particular, courts alone can implement the fullinformation benchmark whenever positive externalities are sufficiently small or courts mistake safe firms as unsafe with sufficiently low probability: inequality (17) is satisfied whenever $\bar{e}$ is sufficiently small (fixing $\varepsilon_{\mathrm{U} \mid \mathrm{S}}$ ) or $\varepsilon_{\mathrm{U} \mid \mathrm{S}}$ is sufficiently small (fixing $\bar{e}$ ).

To illustrate, suppose that, absent the harmful externalities controlled by the negligence rule, the private and social returns to introducing a drug are similar. Then proposition 2 says that there is no welfare benefit from having the FDA make an ex ante determination of whether a drug company should issue a warning of a potential side effect. Likewise, suppose that judges have sufficient expertise that they find that a drug company should have warned physicians of a potential side effect only when issuing such a warning would have in fact been socially efficient. When judges and juries really have such expertise, then there are no additional benefits of regulation either, since negligence assures correct incentives. Matters may be different if the social benefits of drug introduction greatly exceed the private ones and if judges do not have sufficient expertise.

When inequality (17) does not hold, the addition of regulators with relative expertise may be beneficial by reducing safe firms' exposure to liability costs. Before turning to this issue, it is helpful to derive optimal damages under courts alone. When any negligence regime that creates incentives for unsafe firms to take precautions deters safe firms from participating in the market $(\bar{e}>\tilde{e})$, it may be optimal to set damages below the level that incentivizes precautions $(\bar{d})$. The obvious alternative to setting damages at $\bar{d}$ is setting damages at

$$
\underline{d}= \begin{cases}\frac{b-\bar{e}}{\pi_{\mathrm{S}} \varepsilon_{\mathrm{U} \mid \mathrm{S}}} & \text { if } b<\pi_{\mathrm{U}} h \\ 0 & \text { if } b \geq \pi_{\mathrm{U}} h,\end{cases}
$$

which equals either the maximum damage award that does not affect the activity level of safe firms (when $b<\pi_{\mathrm{U}} h$ ) or zero (otherwise). Letting $W(d)$ equal social welfare as a function of the level of damages under negligence and defining $d^{*}$ to equal the smallest maximizer of $W(d)$-namely, $d^{*}=\min \arg \max _{d \geq 0} W(d)$-we have the following result:

Proposition 3. If $\bar{e}>\tilde{e}$, then optimal damages under negligence are given by

$$
d^{*}= \begin{cases}\bar{d} & \text { if } \alpha<\frac{L_{\mathrm{U}}}{L_{\mathrm{U}}+G_{\mathrm{S}}} \\ \underline{d} & \text { if } \alpha \geq \frac{L_{\mathrm{U}}}{L_{\mathrm{U}}+G_{\mathrm{S}}},\end{cases}
$$

where $G_{\mathrm{S}}$ represents the expected gain from increasing a given safe firm's incentive to engage in activity by reducing damages from $\bar{d}$ to $\underline{d}$ and $L_{\mathrm{U}}$ represents the 
expected loss from eliminating a given unsafe firm's incentive to take precautions by reducing damages from $\bar{d}$ to $\underline{d}$ (both $G_{\mathrm{S}}$ and $L_{\mathrm{U}}$ are defined in the Appendix).

Proposition 3 characterizes the optimal negligence regime when positive externalities and court errors are sufficiently large that negligence cannot implement the full-information benchmark. Proposition 3 says that damages should be high enough to create incentives for unsafe firms to take precautions if and only if the proportion of safe firms $(\alpha)$ is sufficiently low. The intuition is that the cost of setting large damages is the loss from deterring safe firms from participating in the market because of court errors; this loss is proportional to the number of safe firms that are affected.

\section{Regulators Alone}

When safe firms capture too low a share of the social surplus generated by their activity and courts mistake safe firms for unsafe ones with a sufficiently high probability $(\bar{e}>\tilde{e})$, then any negligence regime that encourages unsafe firms to take precautions necessarily lowers the activity level of safe firms. In this situation, regulators may help by reducing safe firms' exposure to liability costs while maintaining incentives for at least some unsafe firms to take precautions. We first consider regulation alone (no litigation) and ask when it performs better than courts alone. We then turn to the characterization of the optimal combined regime.

To gain intuition for why regulators may perform better than courts, consider first the extreme case in which regulators perfectly classify firms $\left(\delta_{\mathrm{U} \mid \mathrm{S}}=\right.$ $\delta_{\mathrm{S} \mid \mathrm{U}}=0$ ), and consider the following regulatory regime: firms face a fine $F>$ $c$ for failure to take precautions if they are ex ante classified as unsafe by the regulator and face no fine for failure to take precautions if they are classified as safe. It is clear that this regime implements the full-information benchmark, thus improving on the court-only outcome when $\bar{e}>\tilde{e}$.

More generally $\left(\delta_{\mathrm{U} \mid \mathrm{S}} \geq 0, \delta_{\mathrm{S} \mid \mathrm{U}} \geq 0\right)$, consider the following subset of regulatory regimes. In the event of an accident, a regulator investigates whether a firm took precautions and imposes a fine if the firm failed to do so, where the magnitude of the fine may depend on the regulatory classification. The regulator does not investigate or impose a fine if the firm did not cause an accident. Any enforcement method of this form is described by $\left(f_{\hat{S}}, f_{\hat{U}}\right)$, where $f_{\hat{\theta}} \geq 0$ is the level of fines a firm ex ante classified as type $\hat{\theta} \in\{\hat{S}, \hat{U}\}$ must pay in the case of an accident if it is found to have not taken precautions. Denote the maximum level of social welfare achievable by such an enforcement method by $\tilde{W}^{\mathrm{R}}$.

To illustrate, return to the drug example. Prior to a drug's release, a regulator classifies a drug as safe and unlikely to benefit from warning physicians of a potential side effect or as unsafe and requiring such a warning. The regulator thus requires precautions if and only if the drug is classified as unsafe. If an accident occurs, the regulator investigates whether the company warned phy- 
sicians and imposes a fine if it did not, where the magnitude of the fine can depend on the drug's classification (in particular, the fine may be zero if the regulator had not required precautions).

We can restrict attention to such regimes by the following lemma, in which $W^{\mathrm{R}}$ denotes the maximum level of social welfare achievable by an enforcement regime involving regulators alone.

Lemma 2. $W^{\mathrm{R}}=\tilde{W}^{\mathrm{R}}$.

Lemma 2 establishes that, in our model, there is no loss of generality in confining attention to regulatory regimes in which the regulator investigates whether a firm took precautions only in the event of an accident. In particular, it is suboptimal for a regulator to fine a firm for failure to take precautions prior to an accident occurring. Together with the next proposition, which establishes an upper bound on optimal regulatory fines, lemma 2 implies that commandand-control regulation, whereby the regulator forces all firms classified as some type to take precautions (or, equivalently, sets large enough fines that all such firms are incentivized to take precautions), is suboptimal in our model. The fact that an accident occurs provides an additional signal that a firm is unsafe. Making fines contingent on whether there is an accident thus allows the regulator to set fines that better target unsafe firms. Of course, as the example above illustrated, command-and-control regulation can perform just as well as contingent fines in the special case in which the regulator perfectly classifies firms. Likewise, while suboptimal, command-and-control regulation can perform better than litigation when regulators have sufficient expertise (namely, when $\delta_{\mathrm{U} \mid \mathrm{S}}$ and $\delta_{\mathrm{S} \mid \mathrm{U}}$ are sufficiently small).

What is the optimal combination of $\left(f_{\hat{\mathrm{S}}}, f_{\hat{\mathrm{U}}}\right)$ ? When $\bar{e}>\tilde{e}$, fine $f_{\hat{\theta}}$ should be set by comparing the benefits of creating incentives for unsafe firms to take precautions against the costs of discouraging safe firms from engaging in activity. These benefits and costs will depend on the relative number of safe and unsafe firms affected by the fine. Let

$$
\alpha_{\hat{\mathrm{S}}}=\operatorname{Pr}\left(\mathrm{S} \mid \sigma_{\mathrm{R}}=\hat{\mathrm{S}}\right)=\frac{\left(1-\delta_{\mathrm{U} \mid \mathrm{S}}\right) \alpha}{\left(1-\delta_{\mathrm{U} \mid \mathrm{S}}\right) \alpha+\delta_{\mathrm{S} \mid \mathrm{U}}(1-\alpha)}
$$

denote the fraction of safe firms among those classified by the regulator as safe and

$$
\alpha_{\hat{\mathrm{U}}}=\operatorname{Pr}\left(\mathrm{S} \mid \sigma_{\mathrm{R}}=\hat{\mathrm{U}}\right)=\frac{\delta_{\mathrm{U} \mid \mathrm{S}} \alpha}{\delta_{\mathrm{U} \mid \mathrm{S}} \alpha+\left(1-\delta_{\mathrm{S} \mid \mathrm{U}}\right)(1-\alpha)}
$$

denote the fraction of safe firms among those classified by the regulator as unsafe.

The obvious candidates for the optimal fine are

$$
\bar{f}=\frac{c}{\pi_{\mathrm{U}}},
$$

which equals the minimum fine that creates incentives for unsafe firms to take 
precautions, and

$$
\underline{f}= \begin{cases}\frac{b-\bar{e}}{\pi_{\mathrm{S}}} & \text { if } b<\pi_{\mathrm{U}} h, \\ 0 & \text { if } b \geq \pi_{\mathrm{U}} h,\end{cases}
$$

which equals either the maximum fine that does not affect the activity level of safe firms (when $b<\pi_{\mathrm{U}} h$ ) or zero (otherwise).

Define $W\left(f_{\hat{S}}, f_{\hat{U}}\right)$ to equal social welfare as a function of the level of fines and note that $W\left(f_{\hat{S}}, f_{\hat{U}}\right)$ can be expressed as $\operatorname{Pr}\left(\sigma_{\mathrm{R}}=\hat{\mathrm{S}}\right) W_{\hat{\mathrm{S}}}\left(f_{\hat{\mathrm{S}}}\right)+\operatorname{Pr}\left(\sigma_{\mathrm{R}}=\right.$ $\hat{\mathrm{U}}) W_{\hat{\mathrm{U}}}\left(f_{\hat{\mathrm{U}}}\right)$, where $W_{\hat{\theta}}\left(f_{\hat{\theta}}\right)$ equals expected welfare conditional on the regulator's signal. Finally, let $f_{\hat{\theta}}^{*}$ equal the smallest maximizer of $W_{\hat{\theta}}\left(f_{\hat{\theta}}\right)$; namely, $f_{\hat{\theta}}^{*}=$ $\min \arg \max _{f \geq 0} W_{\hat{\theta}}(f)$.

Proposition 4. Let $\bar{e}>\tilde{e}, \delta_{\mathrm{S} \mid \mathrm{U}}>0$, and $\delta_{\mathrm{U} \mid \mathrm{S}}>0$. Then fines in the optimal regulatory regime are given by

$$
f_{\hat{\mathrm{s}}}^{*}= \begin{cases}\bar{f} & \text { if } \alpha_{\hat{\mathrm{s}}}<\frac{L_{\mathrm{U}}^{\mathrm{R}}}{L_{\mathrm{U}}^{\mathrm{R}}+G_{\mathrm{S}}^{\mathrm{R}}}, \\ \underline{f} & \text { if } \alpha_{\hat{\mathrm{S}}} \geq \frac{L_{\mathrm{U}}^{\mathrm{R}}}{L_{\mathrm{U}}^{\mathrm{R}}+G_{\mathrm{S}}^{\mathrm{R}}},\end{cases}
$$

and

$$
f_{\hat{U}}^{*}= \begin{cases}\bar{f} & \text { if } \alpha_{\hat{\mathrm{U}}}<\frac{L_{\mathrm{U}}^{\mathrm{R}}}{L_{\mathrm{U}}^{\mathrm{R}}+G_{\mathrm{S}}^{\mathrm{R}}}, \\ \underline{f} & \text { if } \alpha_{\hat{\mathrm{U}}} \geq \frac{L_{\mathrm{U}}^{\mathrm{R}}}{L_{\mathrm{U}}^{\mathrm{R}}+G_{\mathrm{S}}^{\mathrm{R}}},\end{cases}
$$

where $G_{S}^{R}$ represents the expected gain from increasing a given safe firm's incentive to engage in activity by reducing fines from $\bar{f}$ to $f$ and $L_{\mathrm{U}}^{\mathrm{R}}$ represents the expected loss from eliminating a given unsafe firm's incentive to take precautions by reducing fines from $\bar{f}$ to $\underline{f}$ (both $G_{\mathrm{S}}^{\mathrm{R}}$ and $L_{\mathrm{U}}^{\mathrm{R}}$ are defined precisely in the Appendix).

Proposition 4 characterizes the optimal regulatory regime when negligence cannot implement the full-information benchmark. Proposition 4 says that fines should be high enough to create incentives for unsafe firms to take precautions if and only if the proportion of safe firms affected by the fine (namely, $\alpha_{\hat{\theta}}$ ) is sufficiently low, since the loss from deterring safe firms from participating in the market by exposing them to large fines is proportional to the number of safe firms that are exposed.

When does regulation alone perform better than litigation? For this to be the case, we must have $\left(f_{\hat{S}}^{*}, f_{\hat{U}}^{*}\right)=(f, \bar{f})$ : the regulatory classification matters. ${ }^{12}$ There are two main cases to consider. In the first case, the optimal negligence regime

\footnotetext{
${ }^{12}$ This follows from the fact that $W(f, f) \leq W(\underline{d})$ and $W(\bar{f}, \bar{f}) \leq W(\bar{d})$, as we show in the proof of proposition 5 in the Appendix.
} 
creates incentives for unsafe firms to take precautions at the cost of discouraging safe firms from engaging in activity. Proposition 3 identifies this as the case in which the proportion of safe firms in the population is sufficiently small: $\alpha<$ $L_{\mathrm{U}} /\left(L_{\mathrm{U}}+G_{\mathrm{S}}\right)$. In this case, regulation may help by reducing safe firms' exposure to fines, while still creating incentives for correctly classified unsafe firms to take precautions. Since the benefit of regulation is proportional to the number of safe firms that are affected in this case, the number of safe firms must lie in some intermediate range for regulation to be optimal: this number must be sufficiently low that the optimal negligence regime creates incentives for unsafe firms to take precautions $\left(d^{*}=\bar{d}\right)$, yet sufficiently high that it is better to instead limit liability costs for some safe firms by moving to regulation with fines ( $f$, $\bar{f})$, at the cost of removing misclassified unsafe firms' incentives to take precautions.

In the second case, the optimal negligence regime does not create incentives for unsafe firms to take precautions because the cost of doing so is too large. Proposition 3 identifies this as the case in which the proportion of safe firms in the population is sufficiently high: $\alpha \geq L_{\mathrm{U}} /\left(L_{\mathrm{U}}+G_{\mathrm{S}}\right)$. In this case, regulation may help by creating incentives for some unsafe firms to take precautions at the cost of discouraging misclassified safe firms from engaging in activity. That is, regulation may help if it is less costly for regulators to create incentives for precautions. Since the cost of regulation is proportional to the number of safe firms that are affected in this case, again the number of safe firms must lie in some intermediate range for regulation to perform better than courts: this number must be sufficiently high that the optimal negligence regime does not create incentives for unsafe firms to take precautions $\left(d^{*}=\underline{d}\right)$, yet sufficiently low that it is better to instead encourage some unsafe firms to take precautions by moving to regulation with fines $(f, \bar{f})$, at the cost of discouraging misclassified safe firms from participating in the market.

In either case, regulation alone performs better than courts alone so long as the fraction of safe firms lies in some intermediate range, where what is intermediate depends on the magnitude of court and regulatory errors. Formally, we have the following proposition:

Proposition 5. Suppose that the conditions of proposition 4 hold.

1. If $\alpha<L_{\mathrm{U}} /\left(L_{\mathrm{U}}+G_{\mathrm{S}}\right)$, then regulation alone performs better than courts alone if and only if $\tilde{G}_{\mathrm{S}}>0$ and

$$
\alpha>\frac{\tilde{L}_{\mathrm{U}}}{\tilde{L}_{\mathrm{U}}+\tilde{G}_{\mathrm{S}}},
$$

where $\tilde{G}_{\mathrm{S}}$ denotes the expected gain (per safe firm) from increasing safe firms' incentive to engage in activity by moving to regulation with fines $(\underline{f}, \bar{f})$ from negligence with damages $\bar{d}$ and $\tilde{L}_{\mathrm{U}}$ denotes the expected loss (per unsafe firm) from removing fraction $\delta_{\mathrm{S} \mid \mathrm{U}}$ of unsafe firms' incentives to take precautions by 
moving to regulation with fines $(\underline{f}, \bar{f})$ from negligence with damages $\bar{d}$ (both $\tilde{G}_{\mathrm{S}}$ and $\tilde{L}_{\mathrm{U}}$ are defined in the Appendix).

2. If $\alpha \geq L_{\mathrm{U}} /\left(L_{\mathrm{U}}+G_{\mathrm{S}}\right)$, then regulation alone performs better than courts alone if and only if $\tilde{G}_{\mathrm{U}}>0$ and

$$
\alpha<\frac{\tilde{G}_{\mathrm{U}}}{\tilde{G}_{\mathrm{U}}+\tilde{L}_{\mathrm{S}}},
$$

where $\tilde{G}_{U}$ denotes the expected gain (per unsafe firm) from encouraging fraction $\left(1-\delta_{\mathrm{S} \mid \mathrm{U}}\right)$ to take precautions by moving from negligence with damages $\underline{d}$ to regulation with fines $(f, \bar{f})$ and $\tilde{L}_{\mathrm{S}}$ denotes the expected loss (per safe firm) from discouraging fraction $\bar{\delta}_{\mathrm{U} \mid \mathrm{S}}$ from engaging in activity by moving from negligence with damages $\underline{d}$ to regulation with fines $(\underline{f}, \bar{f})$ (both $\tilde{G}_{\mathrm{U}}$ and $\tilde{L}_{\mathrm{S}}$ are defined in the Appendix).

One implication of proposition 5 is that regulation alone is superior to litigation alone so long as regulators have sufficient expertise. Formally, the righthand side of inequality $(24)$ is increasing in regulatory errors $\left(\delta_{\mathrm{S} \mid \mathrm{U}}, \delta_{\mathrm{U} \mid \mathrm{S}}\right)$ and tends toward zero as these errors tend toward zero. Similarly, the right-hand side of inequality (25) is decreasing in the size of regulatory errors and tends toward one as these errors tend toward zero.

Another implication is less obvious: regulation alone is (weakly) inferior to litigation alone when courts and regulators are subject to the same errors. Proposition 5 identifies two situations in which regulation alone performs better than courts alone, both of which amount to the fraction of safe firms falling between two bounds, where these bounds depend on court and regulatory errors: the number of safe firms $(\alpha)$ must satisfy $\tilde{L}_{\mathrm{U}} /\left(\tilde{L}_{\mathrm{U}}+\tilde{G}_{\mathrm{S}}\right)<\alpha<L_{\mathrm{U}} /\left(L_{\mathrm{U}}+G_{\mathrm{S}}\right)$, or $L_{\mathrm{U}} /\left(L_{\mathrm{U}}+G_{\mathrm{S}}\right) \leq \alpha<\tilde{G}_{\mathrm{U}} /\left(\tilde{G}_{\mathrm{U}}+\tilde{L}_{\mathrm{S}}\right)$. Neither situation can hold when courts and regulators are subject to the same errors, as in this case the upper bounds fall below the lower bounds: when $\varepsilon_{\mathrm{S} \mid \mathrm{U}}=\delta_{\mathrm{S} \mid \mathrm{U}}$ and $\delta_{\mathrm{U} \mid \mathrm{S}}=\varepsilon_{\mathrm{U} \mid \mathrm{S}}$, we have verified that $\tilde{L}_{\mathrm{U}} /\left(\tilde{L}_{\mathrm{U}}+\tilde{G}_{\mathrm{S}}\right) \geq L_{\mathrm{U}} /\left(L_{\mathrm{U}}+G_{\mathrm{S}}\right)$ and $L_{\mathrm{U}} /\left(L_{\mathrm{U}}+G_{\mathrm{S}}\right) \geq \tilde{G}_{\mathrm{U}} /\left(\tilde{G}_{\mathrm{U}}+\tilde{L}_{\mathrm{S}}\right)$ (calculations provided upon request).

Taken together, these two implications of proposition 5 provide some formal support for Landis's (1938) claim that the central benefit of regulators relative to judges is greater expertise.

\section{Combination of Regulators and Courts}

A regime that combines the use of regulators and courts clearly does at least as well as one that involves only regulators or courts. What does the optimal such regime look like, and when does it in fact require the use of regulators?

Consider enforcement methods involving courts and regulators of the following form: in the case of an accident, a firm is subject to a negligence claim, and the magnitude of damages if found liable may depend on the regulatory clas- 


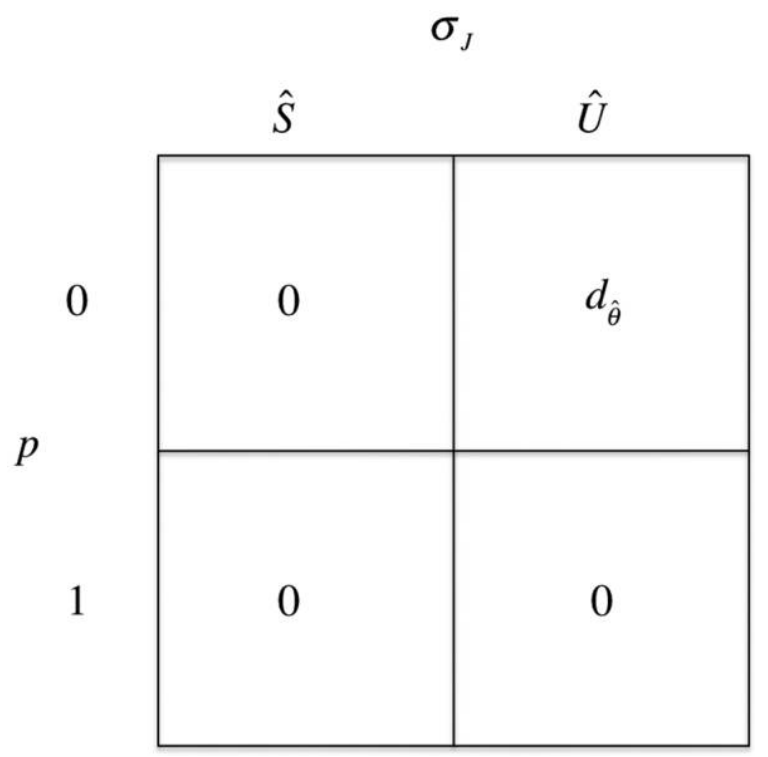

Figure 2. Damages under negligence combined with regulation, where damages are a function of the level of precautions $(p \in\{0,1\})$, the court's signal $\left(\sigma_{\mathrm{I}} \in\{\hat{\mathrm{S}}, \hat{\mathrm{U}}\}\right)$, and the regulatory classification $\left(\sigma_{\mathrm{R}} \in\{\hat{\mathrm{S}}, \hat{\mathrm{U}}\}\right)$.

sification. ${ }^{13}$ As illustrated in Figure 2, any enforcement method involving both regulators and courts of this form is described by $\left(d_{\hat{S}}, d_{\hat{\mathrm{U}}}\right)$, where $d_{\hat{\theta}} \geq 0$ is the the level of damages a firm ex ante classified as type $\hat{\theta} \in\{\hat{\mathrm{S}}$, $\hat{\mathrm{U}}\}$ must pay in the case of an accident if it is found to have not taken precautions and to be unsafe. Since we allow $d_{\hat{S}}=d_{\hat{\mathrm{U}}}$, mixed regimes of this type nest pure negligence. Denote the maximum level of social welfare achievable by such an enforcement method by $W^{\mathrm{N}+\mathrm{R}}$.

To illustrate, return to the drug example. Prior to a drug's release, a regulator determines whether the drug company should warn physicians of a potential side effect while marketing the drug. If an accident occurs, a case against the drug company is brought to court. A judge or jury then determines whether the drug company did and should have warned physicians of a potential side effect. A plaintiff is awarded damages if the court decides (possibly incorrectly) that the drug company should have warned but failed to do so. The magnitude of damages may depend on the regulator's previous classification.

We can restrict attention to such mixed regimes by the following lemma,

${ }^{13}$ It is not important that the court (rather than the regulator) imposes a penalty in the case of an accident. It is important, however, that the penalty can be set taking into account the regulatory classification together with the court's signal. 
where $W^{\mathrm{C}+\mathrm{R}}$ denotes the maximum level of social welfare achievable by an enforcement regime involving both courts and regulators.

Lemma 3. $W^{\mathrm{C}+\mathrm{R}}=W^{\mathrm{N}+\mathrm{R}}$.

Lemma 3 implies that, without loss of generality, we can confine attention to situations where regulators do not perform an enforcement function (namely, the mixed regime illustrated in Figure 2 does not involve the use of regulatory fines). The intuition is that it is best to make incentives for precautions contingent on as much information as possible to maximally target these incentives toward unsafe firms. Regulatory fines are contingent only on information available to the regulator, while court damages are both contingent on this information and the court's signal.

What is the optimal combination of $\left(d_{\hat{\mathrm{S}}}, d_{\hat{\mathrm{U}}}\right)$ ? Define $W\left(d_{\hat{\mathrm{S}}}, d_{\hat{\mathrm{U}}}\right)$ to equal social welfare as a function of the level of damages and note that $W\left(d_{\hat{\mathrm{S}}}, d_{\hat{\mathrm{U}}}\right)$ can be expressed as $\operatorname{Pr}\left(\sigma_{\mathrm{R}}=\hat{\mathrm{S}}\right) W_{\hat{\mathrm{S}}}\left(d_{\hat{\mathrm{S}}}\right)+\operatorname{Pr}\left(\sigma_{\mathrm{R}}=\hat{\mathrm{U}}\right) W_{\hat{\mathrm{U}}}\left(d_{\hat{\mathrm{U}}}\right)$, where $W_{\hat{\theta}}\left(d_{\hat{\theta}}\right)$ equals expected welfare conditional on a firm being classified as $\hat{\theta}$. Finally, let $d_{\hat{\theta}}^{*}$ equal the smallest maximizer of $W_{\hat{\theta}}\left(d_{\hat{\theta}}\right)$; namely, $d_{\hat{\theta}}^{*}=\min \arg \max _{d \geq 0} W_{\hat{\theta}}(d)$.

Proposition 6. Let $\bar{e}>\tilde{e}, \delta_{\mathrm{S} \mid \mathrm{U}}>0$, and $\delta_{\mathrm{U} \mid \mathrm{S}}>0$. Then damages in the optimal combined regime are given by

$$
d_{\hat{\mathrm{s}}}^{*}= \begin{cases}\bar{d} & \text { if } \alpha_{\hat{\mathrm{s}}}<\frac{L_{\mathrm{U}}}{L_{\mathrm{U}}+G_{\mathrm{S}}} \\ \underline{d} & \text { if } \alpha_{\hat{\mathrm{s}}} \geq \frac{L_{\mathrm{U}}}{L_{\mathrm{U}}+G_{\mathrm{S}}},\end{cases}
$$

and

$$
d_{\hat{U}}^{*}= \begin{cases}\bar{d} & \text { if } \alpha_{\hat{U}}<\frac{L_{U}}{L_{\mathrm{U}}+G_{\mathrm{S}}} \\ \underline{d} & \text { if } \alpha_{\hat{\mathrm{U}}} \geq \frac{L_{\mathrm{U}}}{L_{\mathrm{U}}+G_{\mathrm{S}}} .\end{cases}
$$

Proposition 6 characterizes the optimal combined regime when positive externalities and court errors are sufficiently large that the negligence regime alone cannot implement the full-information benchmark. This proposition says that the level of damages faced by firms ex ante classified as unsafe (safe) by the regulator should be set high enough to create incentives for unsafe firms to take precautions if and only if the proportion of safe firms among those classified as unsafe (safe) is sufficiently low.

When does the optimal combined regime in fact make use of regulators?

Definition 1. The optimal regime includes regulation whenever $d_{\hat{S}}^{*} \neq d_{\mathrm{U}}^{*}$.

Corollary 1. Suppose that the conditions of proposition 6 hold. Then the optimal regime includes regulation if and only if 

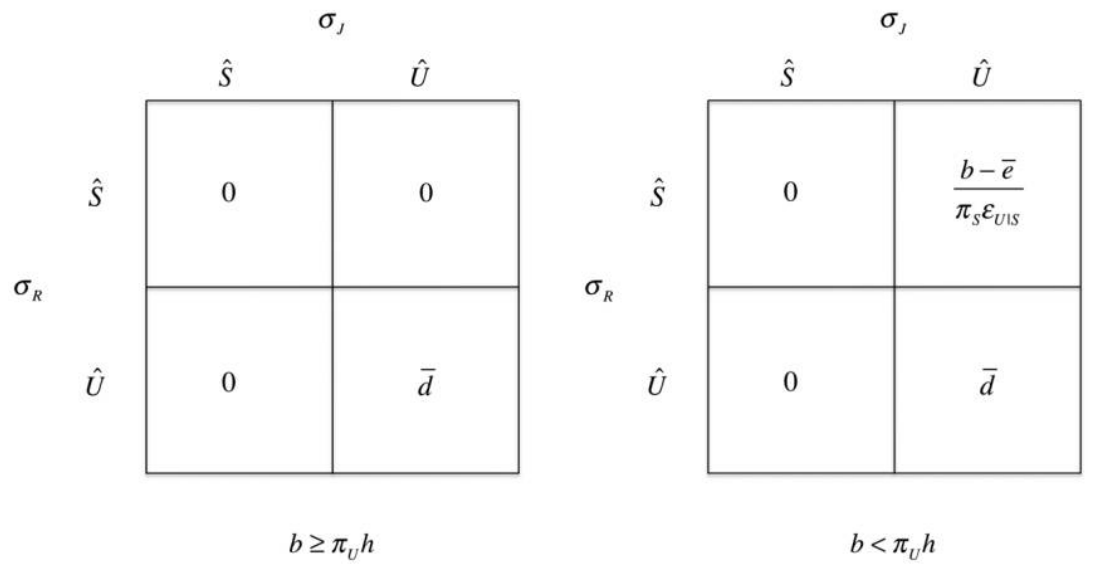

Figure 3. Damages under the optimal regime whenever it includes regulation

$$
\alpha_{\hat{\mathrm{S}}} \geq \frac{L_{\mathrm{U}}}{L_{\mathrm{U}}+G_{\mathrm{S}}}>\alpha_{\hat{\mathrm{U}}} .
$$

By corollary 1, the optimal regime includes regulation if and only if safe firms comprise a large enough fraction of those firms ex ante classified as safe by the regulator and unsafe firms comprise a large enough fraction of those firms classified as unsafe. In particular, regulators increase welfare if and only if they are sufficiently good at determining whether a firm should efficiently take precautions. Formally, $\alpha_{\hat{\mathrm{S}}}$ is decreasing in regulatory errors, $\delta_{\mathrm{S} \mid \mathrm{U}}$ and $\delta_{\mathrm{U} \mid \mathrm{s}}$, and tends to one as these errors approach zero; $\alpha_{\hat{\mathrm{U}}}$ is increasing in these errors and tends to zero as these errors approach zero.

Corollary 2. Suppose the conditions of proposition 6 hold.

1. If $b \geqq \pi_{\mathrm{U}} h$, then whenever the optimal regime includes regulation, $\left(d_{S}^{*}\right.$, $\left.d_{\mathrm{U}}^{*}\right)=(0, \bar{d})$. Compliance with regulatory standards exempts firms from liability.

2. If $b<\pi_{\mathrm{U}} h$, then whenever the optimal regime includes regulation, ( $d_{\mathrm{S}}^{*}$, $\left.d_{\mathrm{U}}^{*}\right)=\left[(b-\bar{e}) /\left(\pi_{\mathrm{S}} \varepsilon_{\mathrm{U} \mid \mathrm{S}}\right), \bar{d}\right]$. Compliance with regulatory standards reduces but does not eliminate liability.

Corollary 2 is illustrated in Figure $3^{14}$ and says that when the optimal law enforcement regime includes regulation and unsafe firms generate positive social returns even if they fail to take precautions, then firms should be granted immunity from future liability if they meet the safety standard set by the regulator.

\footnotetext{
${ }^{14}$ Damages are a function of the regulatory classification $\left(\sigma_{\mathrm{R}} \in\{\hat{\mathrm{S}}, \hat{\mathrm{U}}\}\right)$, the court's signal $\left(\sigma_{\mathrm{J}} \in\right.$ $\{\hat{\mathrm{S}}, \hat{\mathrm{U}}\})$, and the social returns from firm activity $(b)$ as compared to expected harm generated by an unsafe firm that does not take precautions $\left(\pi_{\mathrm{U}} h\right)$. Everything is conditional on a firm not taking precautions (damages are identically zero otherwise).
} 
On the other hand, when unsafe firms generate negative social returns if they fail to take precautions, then firms should be subject to negligence claims even if they meet the standard set by the regulator, but the magnitude of damage awards is lower for firms that meet that standard.

The intuition behind these results is as follows. A pure-negligence regime can always incentivize full-information benchmark precautions for all firms and fullinformation benchmark activity for unsafe firms. In consequence, the addition of regulators can improve matters only when the activity level of safe firms is less than the full-information benchmark under negligence alone. In this case, regulators have the ability to encourage entry by limiting liability costs for safe firms through setting a damage award for firms classified as safe that is lower than the minimum necessary to incentivize precautions among the unsafe firms mistakenly classified as safe. When unsafe firms generate positive social returns in the absence of precautions, a damage award of zero is optimal among awards in this range, since lowering the award encourages greater (and more efficient) activity while bringing out the same level of precautions. On the other hand, when unsafe firms generate negative social returns in the absence of precautions and unsafe firms are sometimes mistakenly classified as safe, it is no longer optimal to set a damage award of zero. This is because it is possible to set a small but positive award that efficiently lowers the level of activity of unsafe firms mistakenly classified as safe, while not affecting the level of activity of safe firms (recall that unsafe firms are more likely to cause harm and be held liable if an accident occurs).

This result may shed light on the important policy question of whether regulation should preempt subsequent litigation against firms that comply with regulatory rules by providing them with safe harbor from future negligence awards. The answer, according to our analysis, turns on whether the social benefits of activity in the particular sphere exceed expected harm from accidents even when firms do not take proper care. For example, for some medical innovations such as vaccines or treatments for the terminally ill, one might think that there is indeed a case for preemption because the social returns are large even with unwarned side effects. On the other hand, in situations such as airplane safety maintenance, where it is difficult to argue that the social benefits of an activity outweigh expected harm when proper care is not taken, our analysis provides no justification for preemption. Rather, the efficient enforcement regime combines regulation with negligence. The general point is that preemption should be quite rare: it requires that activity be so valuable that it should be encouraged even by negligent firms.

\subsection{Benefits and Costs of Revealing Information about Firm Safety Ex Ante}

In a combined regime, regulators are modeled as generating and revealing additional information about firm safety ex ante (prior to a firm's choice of precautions and activity), which allows each firm to respond to its regulatory 
classification. This is how regulation tends to work in practice. It is possible, however, that a more efficient outcome could be achieved if this information was instead revealed ex post, for example, if a regulator appeared as an expert witness at the time of a trial.

The comparison between generating and revealing additional information ex ante and ex post when courts do not have access to any other information (namely, absent the regulatory signal, courts mistake unsafe firms as safe with probability $\frac{1}{2}$ and vice versa) is equivalent to the comparison between the performance of courts and regulators alone when courts and regulators make the same errors (namely, $\varepsilon_{S \mid U}=\delta_{S \mid U}$ and $\varepsilon_{U \mid S}=\delta_{U \mid S}$ ). As mentioned above, using the conditions of proposition 5 , we have verified that courts alone perform (weakly) better than regulators alone when courts and regulators make the same errors. This suggests that, in our model, revealing additional information ex post is weakly better than revealing additional information ex ante. On the other hand, if regulators are better at classifying firms, then there is a case for ex ante regulation. When comparing regulation and litigation alone, the key benefit of regulation comes from the relative expertise of regulators.

\section{Other Regimes}

\subsection{Strict Liability}

Other liability regimes, in particular strict liability, cannot achieve higher levels of welfare than negligence in our model by lemma 1. It is worth explaining in a bit more detail why strict liability, whereby a firm has to pay damages whenever it causes an accident (damages are independent of whether the firm took precautions and the signal of its type), is suboptimal.

To illustrate, consider the case in which negligence with damages $d=\bar{d}$ is optimal among negligence regimes and compare the performance of this regime to the performance of strict liability when damages are set at $d^{\text {SL }}$, where $d^{\text {sL }}$ is the minimum damage award necessary to incentivize unsafe firms to take precautions:

$$
c+\pi_{\mathrm{U}}^{L} d^{\mathrm{SL}}=\pi_{\mathrm{U}} d^{\mathrm{SL}} \Rightarrow d^{\mathrm{SL}}=\frac{c}{\pi_{\mathrm{U}}-\pi_{\mathrm{U}}^{L}} .
$$

Like negligence with damages $d=\bar{d}$, strict liability with damages $d=d^{\text {sL }}$ implements first-best precautions. However, both safe and unsafe firms face greater expected liability costs than under negligence: liability costs for unsafe firms are $\pi_{\mathrm{U}}^{L} d^{\mathrm{SL}}$ versus zero; liability costs for safe firms are $\pi_{\mathrm{S}} d^{\mathrm{SL}}=\pi_{\mathrm{s}} c /\left(\pi_{\mathrm{U}}-\pi_{\mathrm{U}}^{L}\right)$ versus $\pi_{\mathrm{S}} \varepsilon_{\mathrm{U} \mid \mathrm{s}} \bar{d}=\pi_{\mathrm{S}} c \varepsilon_{\mathrm{U} \mid \mathrm{s}} / \pi_{\mathrm{U}}\left(1-\varepsilon_{S \mid \mathrm{U}}\right)$. As a result, activity levels tend to be lower, which leads to welfare losses by assumption $2 .^{15}$

\footnotetext{
${ }^{15}$ It can also easily be shown that strict liability with damages $d$ cannot perform better than negligence with damages $\bar{d}$ for any $d<d^{\text {sL }}$.
} 
Why does negligence perform better than strict liability under the assumptions of our model but not under the assumptions of earlier models of optimal tort rules that incorporate activity (for example, Shavell 1980; Polinsky 1980), in which strict liability with damages equal to harm always achieves the first-best outcome so long as only one party can affect the probability or magnitude of an accident? ${ }^{16}$ The answer is that we relax the assumption that firms fully internalize the gross social benefit of activity (namely, we allow $\bar{e}>0$ ). In this case, strict liability with damages equal to harm may lead to suboptimally low activity. When $\bar{e}=0$, strict liability with damages equal to harm achieves the first-best outcome in our model as well, as illustrated in Section 3.1.

\subsection{Negligence When Damages Equal Harm}

Additional reasons to introduce regulation obtain when courts adjudicating tort claims are restricted to applying a negligence standard and setting damages equal to harm. Such damages are optimal in some circumstances (see, for example, Posner 1972) and standard in many others, perhaps because they compensate the plaintiff for harm and "make him whole" (Shavell 2004, p. 271).

There are at least two additional reasons why introducing regulation may be beneficial when damages are restricted to equal harm. First, with this requirement, negligence may fail to create incentives for firms to take first-best precautions. Introducing regulation can then result in more efficient behavior even absent positive externalities from firm activity (Kolstad, Ulen, and Johnson 1990). With no positive externalities and damages equal to harm, safe firms could inefficiently take precautions if they are often mistakenly found liable, or unsafe firms could fail to take precautions if they are often mistakenly found not liable. With either outcome, regulation that replaces tort liability with more efficiently set regulatory fines (namely, fines that create incentives for first-best precautions) is welfare enhancing. ${ }^{17}$

More interesting, the requirement that courts set damages equal to harm may result in inefficiency because the social loss from some firms avoiding exposure by stopping activity could outweigh the gain from incentivizing those still operating to take precautions. Introducing regulation that preempts tort liability

\footnotetext{
${ }^{16}$ In fact, under the assumptions of the more standard models that incorporate activity, strict liability performs better than negligence. This is a consequence of the fact that these models assume decreasing social benefits but constant costs from firm activity (we instead assume that firms of given safety $\theta$ generate constant-across firms-net social returns to activity conditional on a level of precautions). Combined with the assumption that, in the absence of liability rules, firms fully internalize the social benefit to activity but not the expected harm from accidents stemming from the activity, decreasing social benefits imply that firm activity may be inefficiently high under any regime where expected liability costs are lower than expected harm for some firms given that they take privately optimal levels of care (as is the case under a negligence regime in which firms face zero expected liability costs so long as they take sufficient precautions to meet the standard of care).

${ }^{17}$ Under the assumption of no positive externalities from firm activity, a regulatory regime in which any given firm is fined $c / \pi_{\mathrm{U}}$ if it causes an accident and failed to take precautions results in the first-best outcome. Note, however, that strict liability with damages equal to harm also results in efficient behavior under this assumption.
} 
can increase welfare even in the absence of court errors in determining liability. We now develop a necessary and sufficient condition for this to be the case.

Suppose that courts do not make errors $\left(\varepsilon_{\mathrm{U} \mid \mathrm{S}}=\varepsilon_{\mathrm{S} \mid \mathrm{U}}=0\right)$ and that assumptions 1 and 2 hold. Under negligence with damages equal to harm, the behavior of safe firms is first best since they are never mistakenly held liable. An unsafe firm takes precautions since

$$
c<\pi_{\mathrm{U}} h
$$

(where $\pi_{\mathrm{U}} h$ is the reduction in expected liability costs by taking precautions) and engages in activity if and only if the private benefit of activity exceeds the cost of precautions:

$$
b-e>c .
$$

Hence, the activity level of such firms is

$$
\min \left\{\frac{b-c}{\bar{e}}, 1\right\} .
$$

While unsafe firms take first-best precautions under negligence, their activity is inefficiently low whenever $\bar{e}>b-c$ by equation (31). Welfare may actually be lower under negligence than it would be under laissez-faire because the welfare benefit from incentivizing unsafe firms to take first-best precautions can be outweighed by the resulting cost from a decrease in such firms' activity. ${ }^{18}$ The formal condition is

$$
\left(\pi_{\mathrm{U}}-\pi_{\mathrm{U}}^{L}\right) h-c<\left(1-\min \left\{\frac{b-c}{\bar{e}}, 1\right\}\right)\left(b-c-\pi_{\mathrm{U}}^{L} h\right)
$$

or, equivalently,

$$
b>\pi_{\mathrm{U}} h \text { and } \bar{e}>\frac{(b-c)\left(b-c-\pi_{\mathrm{U}}^{L} h\right)}{b-\pi_{\mathrm{U}} h} .
$$

Examining relation (33) reveals that welfare is higher under laissez faire if and only if both the social benefit to activity exceeds the expected value of any harmful externalities that may result when firms take inefficiently few precautions and the level of positive externalities is sufficiently large. Since relation (33) is also the necessary and sufficient condition for unsafe firms not to take precautions under the full-information benchmark, we have established the following proposition: ${ }^{19}$

Proposition 7. Suppose that $\varepsilon_{\mathrm{U} \mid \mathrm{S}}=\varepsilon_{\mathrm{S} \mid \mathrm{U}}=0$, assumptions 1 and 2 hold, and courts are restricted to setting damages equal to harm. If relation (33) is

\footnotetext{
${ }^{18}$ Note that we have implicitly relaxed assumption 6 .

${ }^{19}$ As before, the full-information benchmark refers to the outcome under a benevolent social planner who can set damages contingent on a firm's type.
} 
not satisfied, then negligence implements the full-information benchmark so there is no room for regulation. On the other hand, if relation (33) holds, then negligence does not implement the full-information benchmark, and this benchmark can be implemented by regulation alone with fines $\left(f_{\hat{\mathrm{S}}}, f_{\hat{\mathrm{U}}}\right)=(0,0)$.

Proposition 7 says that when courts implement inefficient precautions once the social loss from some unsafe firms avoiding costs by not operating is taken into account, it is optimal to introduce regulation that effectively shields all firms from tort liability. One interpretation for why courts might implement such inefficient precautions is that, in performing the cost-benefit analysis that leads to a stringent safety standard for firms deemed to be unsafe, courts narrowly define costs: they consider only private costs of taking precautions and ignore the social loss that will result from driving firms out of business. ${ }^{20}$

\section{Conclusion}

As standard law and economics arguments teach us, private contracting and tort liability can accomplish a great deal in controlling social harms. Finding room for socially desirable regulation is not easy, especially for large firms that can afford to pay damages. We have explored the circumstances under which regulation might nonetheless be socially desirable. The central assumptions of our model are the following. First, social control of risks affects activity levels and not just precautions. Second, aside from the adverse risks, social returns to activity might exceed private returns. The second assumption in particular has not been explored in this area, even though we believe that it is plausible in many circumstances, especially when the economy does not operate at full employment.

For this model, we have reported two principal findings. First, having regulators make an ex ante determination of which firms should take particular precautions might be socially desirable, even if the regulators make mistakes. The benefits of regulation depend on the extent to which the social benefits of the activity exceed the private benefits and on the size of court and regulatory errors. This implies, in particular, that the case for regulation is relatively easier to make when regulators have expertise and when the activities in question generate substantial positive externalities. In our view, this argument suggests that regulation should be quite common. In many areas of modern society, social control requires greater expertise than courts are likely to possess (Landis 1938). Moreover, benefits from increasing economic activity could be substantial not

\footnotetext{
${ }^{20}$ Symmetrically, consider the alternative scenario in which there are additional negative externalities to firm activity beyond those controlled by the negligence rule with damages equal to harm (namely, $e<0$ ). In this case, too many firms may choose to operate under negligence with damages equal to harm (for example, if $b<0$ ), and introducing regulation that deters firms from operating may be welfare improving.
} 
just because of technological externalities such as innovation but because such increases save public funds.

The second finding describes the optimal regulatory rule and, in particular, addresses the question of whether regulation should preempt subsequent tort litigation. We have found that if social returns to activity are high enough relative to the harm from insufficient precautions, it is efficient to grant firms complying with regulations safe harbor from subsequent tort liability. If social returns to activity are not so high, it is still desirable to reduce tort liability for complying firms but not to eliminate it entirely. In our view, then, preemption should be relatively rare, since it requires the benefits from economic activity to be so high that it is acceptable for society to excuse negligence in the taking of precautions. The paper has thus suggested some ingredients of an efficient regulatory regime; the optimal solution of course depends on the circumstances of each market.

\section{Appendix}

\section{Omitted Proofs}

\section{A1. Proofs of Lemmas}

Proof of Lemma 1. We can write

$$
\begin{aligned}
W^{\mathrm{C}} & =\max _{D\left(p, \sigma_{\mathrm{J}}\right)} \mathcal{W} \\
& =\alpha \mathbf{E}_{e}\left[y_{\mathrm{S}}(e)\right]\left(b-c p_{\mathrm{S}}-\pi_{\mathrm{S}} h\right)+(1-\alpha) \mathbf{E}_{e}\left[y_{\mathrm{U}}(e)\right]\left(b-c p_{\mathrm{U}}-\pi_{\mathrm{U}}\left(p_{\mathrm{U}}\right) h\right),
\end{aligned}
$$

subject to

1. $p_{\mathrm{S}}=1 \Longleftrightarrow c \leq \pi_{\mathrm{S}}\left\{\mathbf{E}_{\sigma_{\mathrm{J}}}\left[D\left(0, \sigma_{\mathrm{J}}\right) \mid \theta=S\right]-\mathbf{E}_{\sigma_{\mathrm{I}}}\left[D\left(1, \sigma_{\mathrm{J}}\right) \mid \theta=S\right]\right\}$,

2. $p_{\mathrm{U}}=1 \Longleftrightarrow c \leq \pi_{\mathrm{U}} \mathbf{E}_{\sigma_{\mathrm{I}}}\left[D\left(0, \sigma_{\mathrm{J}}\right) \mid \theta=U\right]-\pi_{\mathrm{U}}^{L} \mathbf{E}_{\sigma_{\mathrm{I}}}\left[D\left(1, \sigma_{\mathrm{J}}\right) \mid \theta=U\right]$,

3. $y_{\mathrm{S}}(e)=1 \Longleftrightarrow e \leq b-p_{\mathrm{S}} c-\pi_{\mathrm{S}} \mathbf{E}_{\sigma_{\mathrm{I}}}\left[D\left(p_{\mathrm{S}}, \sigma_{\mathrm{J}}\right) \mid \theta=S\right]$, and

4. $y_{\mathrm{U}}(e)=1 \Longleftrightarrow e \leq b-p_{\mathrm{U}} c-\pi_{\mathrm{U}}\left(p_{\mathrm{U}}\right) \mathbf{E}_{\sigma_{\mathrm{I}}}\left[D\left(p_{\mathrm{U}}, \sigma_{\mathrm{J}}\right) \mid \theta=U\right]$,

where $p_{\theta}$ stands for whether precautions are taken by type $\theta$ firms and $y_{\theta}(e)$ stands for whether a type $(\theta, e)$ firm engages in activity.

Step 1. At the optimum, $p_{\mathrm{s}}=0$.

Fix a solution to the problem $D^{\star}$ and suppose that $D^{\star}$ implements $p_{\mathrm{S}}=$ $p_{\mathrm{S}}^{*}=1$. Welfare under this schedule is given by

$$
W^{\star}=\alpha \bar{y}_{\mathrm{S}}^{\star}\left(b-c-\pi_{\mathrm{S}} h\right)+(1-\alpha) \bar{y}_{\mathrm{U}}^{\star}\left[b-c p_{\mathrm{U}}^{\star}-\pi_{\mathrm{U}}\left(p_{\mathrm{U}}^{\star}\right) h\right],
$$

where $\bar{y}_{\theta}^{\star}$ stands for the activity level among type $\theta$ firms under $D^{\star}(\cdot)$.

Now consider the alternative damage schedule $D^{\prime}(\cdot)$, with $D^{\prime}(0, \hat{S})=D^{\prime}(1$, $\hat{S})=D^{\prime}(1, \hat{U})=0$ and $D^{\prime}(0, \hat{U})=c /\left[\left(1-\varepsilon_{S \mid \mathrm{U}}\right) \pi_{\mathrm{U}}\right]$. Under this alternative schedule, unsafe firms take precautions and safe firms do not. Welfare is given by

$$
W^{\prime}=\alpha \bar{y}_{\mathrm{S}}^{\prime}\left(b-\pi_{\mathrm{S}} h\right)+(1-\alpha) \bar{y}_{\mathrm{U}}^{\prime}\left(b-c-\pi_{\mathrm{U}}^{L} h\right) .
$$


The first term of equation (A3) is larger than the first term of equation (A2) because $\bar{y}_{\mathrm{S}}^{\prime} \geq \bar{y}_{\mathrm{S}}^{\star}$ and $b-\pi_{\mathrm{S}} h(>0)>b-c-\pi_{\mathrm{S}} h$. In addition, the second term of equation (A3) is larger than the second term of equation (A2). This is clear when $p_{\mathrm{U}}^{*}=1$ : in this case, $\bar{y}_{\mathrm{U}}^{\prime} \geq \bar{y}_{\mathrm{U}}^{*}\left(\right.$ since $\left.D^{\prime}(1, \hat{U})=D^{\prime}(1, \hat{S})=0\right)$, so $(1-$ $\alpha) \bar{y}_{\mathrm{U}}^{\prime}\left(b-c-\pi_{\mathrm{U}}^{L} h\right) \geq(1-\alpha) \bar{y}_{\mathrm{U}}^{\star}\left(b-c-\pi_{\mathrm{U}}^{L} h\right)$ by assumption 2 . When $p_{\mathrm{U}}^{*}=0$, we need to compare $(1-\alpha) \bar{y}_{\mathrm{U}}^{\prime}\left(b-c-\pi_{\mathrm{U}}^{L} h\right)$ and $(1-\alpha) \bar{y}_{\mathrm{U}}^{\star}\left(b-\pi_{\mathrm{U}} h\right)$. But we know that the first expression exceeds the second by assumptions 2 and 6 . Since $W^{\prime}>W^{\star}$, we must have $p_{\mathrm{s}}=0$ at the optimum.

Step 2. There is always a solution to the problem with $D(0, \hat{S})=0$.

Fix a solution $D^{\star}(\cdot)$ and suppose that $D^{\star}(0, \hat{S})>0$. Consider alternative schedule $D^{\prime}(\cdot)$, where $D^{\prime}(0, \hat{S})=0, D^{\prime}(0, \hat{U})=D^{\star}(0, \hat{U})+\left[D^{\star}(0, \hat{S}) \varepsilon_{S \mid \mathrm{U}}\right] /\left(1-\varepsilon_{\mathrm{S} \mid \mathrm{U}}\right)$ and $D^{\prime}\left(1, \sigma_{\mathrm{J}}\right) \equiv D^{\star}\left(1, \sigma_{\mathrm{J}}\right)$. Simple algebra yields $p_{\mathrm{U}}^{\prime}=p_{\mathrm{U}}^{*}, \bar{y}_{\mathrm{U}}^{\prime}=\bar{y}_{\mathrm{U}}^{*}, p_{\mathrm{S}}^{\prime}=$ $p_{S}^{\star}=0$ (using step 1 ), and $\bar{y}_{S}^{\prime} \geq \bar{y}_{s}^{\star}$. Hence, $W^{\prime} \geq W^{\star}$, which implies that $D^{\prime}$ is also a solution to the problem.

Step 3. There is always a solution to the problem with $D(0, \hat{S})=D(1$, $\hat{U})=D(1, \hat{S})=0$.

Fix a solution $D^{\star}(\cdot)$ with the property that $D^{\star}(0, \hat{S})=0$. Further, assume that $D^{\star}(1, \hat{U})>0$ or $D^{\star}(1, \hat{S})>0$. Suppose first that $D^{\star}(\cdot)$ implements $p_{U}=1$ (so, in particular, $\left.D^{\star}(0, \hat{U}) \geq c /\left[\pi_{\mathrm{U}}\left(1-\varepsilon_{\mathrm{S} \mid \mathrm{U}}\right)\right]\right)$ and consider the alternative schedule $D^{\prime}(\cdot)$, where $D^{\prime}(0, \hat{U})=c /\left[\pi_{U}\left(1-\varepsilon_{S \mid U}\right)\right]$ and $D^{\prime}(0, \hat{S})=D^{\prime}(1, \hat{S})=D^{\prime}(1, \hat{U})=$ 0 . Simple algebra yields $p_{\mathrm{U}}^{\prime}=p_{\mathrm{U}}^{*}, p_{\mathrm{S}}^{\prime}=p_{\mathrm{S}}^{\star}, \bar{y}_{\mathrm{U}}^{\prime} \geq \bar{y}_{\mathrm{U}}^{\star}$, and $\bar{y}_{\mathrm{S}}^{\prime} \geq \bar{y}_{\mathrm{S}}^{*}$. Hence, $W^{\prime} \geq W^{*}$, which implies that $D^{\prime}$ is also a solution to the problem.

Now suppose that $D^{\star}(\cdot)$ implements $p_{\mathrm{U}}=0$. Consider the alternative schedule $D^{\prime}(\cdot)$, where $D^{\prime}(1, \hat{S})=D^{\prime}(1, \hat{U})=0, D^{\prime}(0, \hat{S})=D^{*}(0, \hat{S})=0$, and $D^{\prime}(0$, $\hat{U})=D^{*}(0, \hat{U})$. So long as $p_{U}^{\prime}=p_{S}^{\prime}=0$, it is easy to see that $\bar{y}_{S}^{\prime}=\bar{y}_{S}^{*}$ and $\bar{y}_{\mathrm{U}}^{\prime}=\bar{y}_{\mathrm{U}}^{*}$, which implies that $W^{\prime}=W^{\star}$ and that $D^{\prime}(\cdot)$ is also a solution to the problem. It is thus left to show that $p_{\mathrm{U}}^{\prime}=p_{\mathrm{S}}^{\prime}=0$, or $c>\pi_{\mathrm{U}}\left(1-\varepsilon_{\mathrm{S} \mid \mathrm{U}}\right) D^{\prime}(0$, $\hat{U})=\pi_{\mathrm{U}}\left(1-\varepsilon_{\mathrm{S} \mid \mathrm{U}}\right) D^{\star}(0, \hat{U})$.

To this end, note that, as a consequence of $D^{\star}(\cdot)$ being optimal, welfare under $D^{\star}(\cdot)$ must be higher than welfare under any damage award function that implements $p_{\mathrm{U}}=1$ :

$$
\begin{aligned}
W^{\star}= & (1-\alpha) \min \left\{1, \frac{b-\pi_{\mathrm{U}}\left(1-\varepsilon_{\mathrm{S} \mid \mathrm{U}}\right) D^{\star}(0, \hat{U})}{\bar{e}}\right\}\left(b-\pi_{\mathrm{U}} h\right) \\
& +\alpha \min \left\{1, \frac{b-\pi_{\mathrm{S}} \varepsilon_{\mathrm{U} \mid \mathrm{S}} D^{\star}(0, \hat{U})}{\bar{e}}\right\}\left(b-\pi_{\mathrm{S}} h\right) \\
\geq & (1-\alpha) \min \left\{1, \frac{b-c}{\bar{e}}\right\}\left(b-c-\pi_{\mathrm{U}}^{L} h\right) \\
& +\alpha \min \left\{1, \frac{b-\pi_{\mathrm{S}} \varepsilon_{\mathrm{U} \mid \mathrm{S}} \bar{d}}{\bar{e}}\right\}\left(b-\pi_{\mathrm{S}} h\right) .
\end{aligned}
$$


By assumptions 2 and 6 , we have that

$$
\begin{gathered}
(1-\alpha) \min \left\{1, \frac{b-c}{\bar{e}}\right\}\left(b-c-\pi_{\mathrm{U}}^{L} h\right) \\
>(1-\alpha) \min \left\{1, \frac{b-\pi_{\mathrm{U}}\left(1-\varepsilon_{\mathrm{S} \mid \mathrm{U}}\right) D^{\star}(0, \hat{U})}{\bar{e}}\right\}\left(b-\pi_{\mathrm{U}} h\right) .
\end{gathered}
$$

Thus, a necessary condition for equation (A4) to hold is

$$
\begin{gathered}
\alpha \min \left\{1, \frac{b-\pi_{\mathrm{S}} \varepsilon_{\mathrm{U} \mid \mathrm{S}} D^{\star}(0, \hat{U})}{\bar{e}}\right\}\left(b-\pi_{\mathrm{S}} h\right) \\
>\alpha \min \left\{1, \frac{b-\pi_{\mathrm{S}} \varepsilon_{\mathrm{U} \mid \mathrm{S}} \bar{d}}{\bar{e}}\right\}\left(b-\pi_{\mathrm{S}} h\right),
\end{gathered}
$$

or $\left[b-\pi_{\mathrm{S}} \varepsilon_{\mathrm{U} \mid \mathrm{S}} D^{\star}(0, \hat{U})\right] / \bar{e}>\left(b-\pi_{\mathrm{S}} \varepsilon_{\mathrm{U} \mid \mathrm{S}} \bar{d}\right) / \bar{e}$, which implies that $c>\pi_{\mathrm{U}}(1-$ $\left.\varepsilon_{\mathrm{S} \mid \mathrm{U}}\right) D^{\star}(0, \hat{U})$. Q.E.D.

Proof of Lemma 2. We can write

$$
\begin{aligned}
W^{\mathrm{R}}= & \max _{F_{\hat{S}}(p, a), \hat{\mathrm{U}}(p, a)} \mathcal{W} \\
= & \sum_{\hat{\theta}} \operatorname{Pr}\left(\sigma_{\mathrm{R}}=\hat{\theta}\right)\left[\alpha_{\hat{\theta}} \mathbf{E}_{e}\left[y_{\mathrm{S} \mid \hat{\theta}}(e)\right]\left(b-c p_{\mathrm{S} \mid \hat{\theta}}-\pi_{\mathrm{S}} h\right)\right. \\
& \left.+\left(1-\alpha_{\hat{\theta}}\right) \mathbf{E}_{e}\left[y_{\mathrm{U} \mid \hat{\theta}}(e)\right]\left(b-c p_{\mathrm{U} \mid \hat{\theta}}-\pi_{\mathrm{U}}\left(p_{\mathrm{U} \mid \hat{\theta}}\right) h\right)\right],
\end{aligned}
$$

subject to

1. $p_{\mathrm{S} \mid \hat{\theta}}=1 \Longleftrightarrow c \leq\left(1-\pi_{\mathrm{S}}\right)\left[F_{\hat{\theta}}(0,0)-F_{\hat{\theta}}(1,0)\right]+\pi_{\mathrm{S}}\left[F_{\hat{\theta}}(0,1)-F_{\hat{\theta}}(1,1)\right]$,

2. $p_{\mathrm{U} \mid \hat{\theta}}=1 \Longleftrightarrow c \leq\left(1-\pi_{\mathrm{U}}\right) F_{\hat{\theta}}(0,0)-\left(1-\pi_{\mathrm{U}}^{L}\right) F_{\hat{\theta}}(1,0)+\pi_{\mathrm{U}} F_{\hat{\theta}}(0,1)-$ $\pi_{\mathrm{U}}^{L} F_{\hat{\theta}}(1,1)$,

3. $y_{\mathrm{S} \mid \hat{\theta}}(e)=1 \Longleftrightarrow e \leq b-p_{\mathrm{S} \mid \hat{\theta}} c-\mathbf{E}_{a}\left[F_{\hat{\theta}}\left(p_{\mathrm{S} \mid \hat{\theta}}, a\right) \mid \theta=S\right]$, and

4. $y_{\mathrm{U} \mid \hat{\theta}}(e)=1 \Longleftrightarrow e \leq b-p_{\mathrm{U} \mid \hat{\theta}} c-\mathbf{E}_{a}\left[F_{\hat{\theta}}\left(p_{\mathrm{U} \mid \hat{\theta}}, a\right) \mid \theta=U\right]$,

where $F_{\hat{\theta}}$ denotes the fine schedule conditional on a firm being classified as $\hat{\theta}$, $p_{\theta \mid \hat{\theta}}$ stands for whether type $\theta$ firms classified as $\hat{\theta}$ take precautions, and $y_{\theta \mid \hat{\theta}}(e)$ stands for whether a type $(\theta, e)$ firm classified as $\hat{\theta}$ engages in activity.

Since fines faced by firms classified as $\hat{S}$ do not affect the behavior of firms classified as $\hat{U}$ and vice versa, we can proceed by characterizing a given $F_{\hat{\theta}}$. For future reference, denote welfare generated by firms classified as $\theta$ by $W_{\hat{\theta}}$; namely, $W_{\hat{\theta}}=\alpha_{\hat{\theta}} \bar{y}_{\mathrm{S} \mid \hat{\theta}}\left(b-c p_{\mathrm{S} \mid \hat{\theta}}-\pi_{\mathrm{S}} h\right)+\left(1-\alpha_{\hat{\theta}}\right) \bar{y}_{\mathrm{U} \mid \hat{\theta}}\left(b-c p_{\mathrm{U} \mid \hat{\theta}}-\pi_{\mathrm{U}}\left(p_{\mathrm{U} \mid \hat{\theta}}\right) h\right)$.

Step 1. At the optimum, $p_{\mathrm{S} \mid \hat{\theta}}=0$.

Fix a solution to the problem $F_{\theta}^{\star}$ and suppose that $F_{\theta}^{\star}$ implements $p_{\mathrm{S} \mid \hat{\theta}}=$ $p_{S}^{\star} \mid \hat{\theta}=1$. Welfare generated by firms classified as $\hat{\theta}$ under this schedule is given by

$$
W_{\hat{\theta}}^{\star}=\alpha_{\hat{\theta}} \bar{y}_{\mathrm{S} \mid \hat{\theta}}^{\star}\left(b-c-\pi_{\mathrm{S}} h\right)+\left(1-\alpha_{\hat{\theta}}\right) \bar{y}_{\mathrm{U} \mid \hat{\theta}}^{\star}\left[b-c p_{\mathrm{U} \mid \hat{\theta}}^{\star}-\pi_{\mathrm{U}}\left(p_{\mathrm{U} \mid \hat{\theta}}^{\star}\right) h\right] .
$$


Now consider alternative fine schedule $F_{\hat{\theta}}^{\prime}$ with $F_{\hat{\theta}}^{\prime}(p, a)=c / \pi_{\mathrm{U}}$ if $p=0$ and $a=1$ and with $F_{\hat{\theta}}^{\prime}(p, a)=0$ otherwise. Welfare generated by firms classified as $\hat{\theta}$ under this schedule is given by

$$
W_{\hat{\theta}}^{\prime}=\alpha_{\hat{\theta}} \bar{y}_{\mathrm{S} \mid \hat{\theta}}^{\prime}\left(b-\pi_{\mathrm{S}} h\right)+\left(1-\alpha_{\hat{\theta}}\right) \bar{y}_{\mathrm{U} \mid \hat{\theta}}^{\prime}\left(b-c-\pi_{\mathrm{U}}^{L} h\right) .
$$

It is easy to verify that equation (A7) is larger than equation (A6) (the argument is analagous to the argument that equation [A3] exceeds equation [A2] in the proof of lemma 1). Thus, $W_{\hat{\theta}}^{\prime}>W_{\hat{\theta}}^{*}$, which implies that $p_{\mathrm{s} \mid \hat{\theta}}=0$ at the optimum.

Step 2. There is always a solution to the problem with $F_{\hat{\theta}}(0,0)=0$.

Fix a solution $F_{\theta}^{*}$ and suppose that $F_{\theta}^{*}(0,0)>0$. Consider alternative schedule $F_{\hat{\theta}}^{\prime}$, where $F_{\hat{\theta}}^{\prime}(0,1)=\left[\left(1-\pi_{\mathrm{U}}\right) / \pi_{\mathrm{U}}\right] F_{\theta}^{*}(0,0)+F_{\theta}^{*}(0,1), F_{\hat{\theta}}^{\prime}(0,0)=0$, and $F_{\hat{\theta}}^{\prime}(1$, $a) \equiv F_{\theta}^{*}(1, a)$. Simple algebra yields $p_{\mathrm{U} \mid \hat{\theta}}^{\prime}=p_{\mathrm{U} \mid \hat{\theta}}^{*}, \bar{y}_{\mathrm{U} \mid \hat{\theta}}^{\prime}=\bar{y}_{\mathrm{U} \mid \hat{\theta}}^{*}, p_{\mathrm{S} \mid \hat{\theta}}^{\prime}=p_{\mathrm{S} \mid \hat{\theta}}^{*}=0$ (by step 1), and $\bar{y}_{S \mid \hat{\theta}}^{\prime} \geq \bar{y}_{S \mid \hat{\theta}}^{*}$. Hence, $W_{\hat{\theta}}^{\prime} \geq W_{\hat{\theta}}^{*}$, which implies that $F_{\hat{\theta}}^{\prime}$ is also a solution to the problem.

Step 3. There is always a solution to the problem with $F_{\hat{\theta}}(0,0)=F_{\hat{\theta}}(1$, $0)=0$.

Fix a solution to the problem with $F_{\theta}^{\star}(1,0)>0$ and $F_{\theta}^{\star}(0,0)=0$. Suppose first that $F_{\hat{\theta}}^{*}$ implements $p_{\mathrm{U} \mid \hat{\theta}}=1$ (so, in particular, $F_{\hat{\theta}}^{\star}(0,1) \geq c / \pi_{\mathrm{U}}$ ), and consider alternative schedule $F_{\hat{\theta}}^{\prime}$, where $F_{\hat{\theta}}^{\prime}(0,1)=c / \pi_{\mathrm{U}}$ and $F_{\hat{\theta}}^{\prime}(1,1)=F_{\hat{\theta}}^{\prime}(0,0)=$ $F_{\hat{\theta}}^{\prime}(1,0)=0$. Simple algebra yields $p_{\mathrm{U} \mid \hat{\theta}}^{\prime}=p_{\mathrm{U} \mid \hat{\theta}}^{*}=1, \bar{y}_{\mathrm{U} \mid \hat{\theta}}^{\prime} \geq \bar{y}_{\mathrm{U} \mid \hat{\theta}}^{*}, p_{\mathrm{S} \mid \hat{\theta}}^{\prime}=$ $p_{S \mid \hat{\theta}}^{*}=0$, and $\bar{y}_{S \mid \hat{\theta}}^{\prime} \geq \bar{y}_{S \mid \hat{\theta}}^{*}$. Hence, $W_{\hat{\theta}}^{\prime} \geq W_{\hat{\theta}}^{*}$, which implies that $F_{\hat{\theta}}^{\prime}$ is also a solution to the problem.

Now suppose that $F_{\theta}^{\star}$ implements $p_{\mathrm{U} \mid \hat{\theta}}=0$, and consider alternative schedule $F_{\hat{\theta}}^{\prime}$, where $F_{\hat{\theta}}^{\prime}(1,0)=0, F_{\hat{\theta}}^{\prime}(1,1)=\infty$, and $F_{\hat{\theta}}^{\prime}(0, a)=F_{\hat{\theta}}^{*}(0, a)$ for $a=0$, 1 . We have $p_{\mathrm{U} \mid \hat{\theta}}^{\prime}=p_{\mathrm{U} \mid \hat{\theta}}^{\star}=p_{S \mid \hat{\theta}}^{\prime}=p_{S \mid \hat{\theta}}^{*}=0, \bar{y}_{\mathrm{U} \mid \hat{\theta}}^{\prime}=\bar{y}_{\mathrm{U} \mid \hat{\theta}}^{*}$, and $\bar{y}_{\mathrm{S} \mid \hat{\theta}}^{\prime}=\bar{y}_{S \mid \hat{\theta}}^{\star}$, which implies that $W_{\hat{\theta}}^{\prime}=W_{\hat{\theta}}^{*}$. As a result, $F_{\hat{\theta}}^{\prime}$ is also a solution to the problem.

From steps $1-3$, the problem of maximizing $W_{\hat{\theta}}\left(F_{\hat{\theta}}\right)$ boils down to selecting $F_{\hat{\theta}}(p, 1)$ for $p=0,1$ (that is, setting fines incurred in the case of an accident). But the behavior of a given firm under $F_{\hat{\theta}}(p, 1)$ is the same as its behavior under damage schedule $D(p, \hat{U})=2 F_{\hat{\theta}}(p, 1)$ (where $D(p, \hat{S})=0$ for $\left.p=0,1\right)$ in the special case where $\varepsilon_{\mathrm{S} \mid \mathrm{U}}=\varepsilon_{\mathrm{U} \mid \mathrm{S}}=\frac{1}{2}$. It follows from lemma 1, then, that there is always a solution to the problem where the firm does not face a fine if it takes precautions. Combined with steps $1-3$, we have shown that there is always a solution to the problem with $F_{\hat{\theta}}(0,0)=F_{\hat{\theta}}(1,0)=F_{\hat{\theta}}(1,1)=0$. Q.E.D.

Proof of Lemma 3. In a combined regime, a firm classified as type $\hat{\theta}$ faces total liability schedule

$$
\mathrm{TL}_{\hat{\theta}}\left(p, \sigma_{\mathrm{J}}, a\right)=(1-a) F_{\hat{\theta}}(p, 0)+a\left(F_{\hat{\theta}}(p, 1)+D_{\hat{\theta}}\left(p, \sigma_{\mathrm{J}}\right)\right),
$$

where $F_{\hat{\theta}}$ stands for regulatory fines and $D_{\hat{\theta}}$ stands for court-imposed damages faced by a firm classified as $\hat{\theta}$.

By an argument mirroring the argument establishing steps 1-3 in the proof 
of lemma 2, there is always a solution to the problem with $F_{\hat{\theta}}(p, 0)=0$ for $p=0,1$. That is, there is always a solution to the problem in which the firm does not incur a fine if it does not cause an accident.

In a combined regime, then, it is without loss of generality to suppose that the firm faces liability schedule $\operatorname{TL}_{\hat{\theta}}\left(p, \sigma_{\mathrm{I}}, 1\right)=F_{\hat{\theta}}(p, 1)+D_{\hat{\theta}}\left(p, \sigma_{\mathrm{I}}\right) \equiv \tilde{D}_{\hat{\theta}}(p$, $\left.\sigma_{\mathrm{I}}\right)$. The problem of maximizing $W_{\hat{\theta}}$ (namely, expected welfare conditional on a firm being classified as type $\hat{\theta}$ ) with respect to $\tilde{D}_{\hat{\theta}}\left(p, \sigma_{\mathrm{J}}\right)$ is the same as the problem of maximizing $W$ with respect to $D\left(p, \sigma_{\mathrm{I}}\right)$, replacing population weights $(\alpha$, $1-\alpha)$ with $\left(\alpha_{\hat{\theta}}, 1-\alpha_{\hat{\theta}}\right)$. The result then follows from lemma 1. Q.E.D.

\section{A2. Proofs of Propositions}

To prove proposition 3, we will make use of the following lemma.

Lemma 4. $d^{*} \in\{\underline{d}, \bar{d}\}$.

Proof. We will prove this lemma through a sequence of claims.

Claim 1. $d^{*} \leq \bar{d}$.

Proof of Claim. Clearly $d^{*} \leq c /\left(\pi_{\mathrm{S}} \varepsilon_{\mathrm{U} \mid \mathrm{S}}\right)$ because it is inefficient to create incentives for safe firms to take precautions (see the proof of lemma 1). For $d \in\left[\bar{d}, c /\left(\pi_{\mathrm{S}} \varepsilon_{\mathrm{U} \mid \mathrm{S}}\right)\right]$, we have

$$
W(d)=\alpha \frac{b-\pi_{\mathrm{S}} \varepsilon_{\mathrm{U} \mid \mathrm{S}} d}{\bar{e}}\left(b-\pi_{\mathrm{S}} h\right)+(1-\alpha) \frac{b-c}{\bar{e}}\left(b-c-\pi_{\mathrm{U}}^{L} h\right) .
$$

For any $d$ in $\left[\bar{d}, c /\left(\pi_{\mathrm{S}} \varepsilon_{\mathrm{U} \mid \mathrm{S}}\right)\right]$,

$$
W^{\prime}(d)=-\frac{\pi_{\mathrm{S}} \varepsilon_{\mathrm{U} \mid S}}{\bar{e}}\left(b-\pi_{\mathrm{S}} h\right)<0,
$$

so $d^{*} \notin(\bar{d}, \infty)$.

Claim 2. If $d^{*}<\bar{d}$, then $d^{*}=\underline{d}$.

Proof of Claim.

Case 1. $b \geq \pi_{\mathrm{U}} h$.

For $d<\bar{d}$, we have

$$
\begin{aligned}
W(d)= & \alpha \min \left\{\frac{b-\pi_{\mathrm{S}} \varepsilon_{\mathrm{U} \mid \mathrm{S}} d}{\bar{e}}, 1\right\}\left(b-\pi_{\mathrm{S}} h\right) \\
& +(1-\alpha) \min \left\{\frac{b-\pi_{\mathrm{U}}\left(1-\varepsilon_{\mathrm{S} \mid \mathrm{U}}\right) d}{\bar{e}}, 1\right\}\left(b-\pi_{\mathrm{U}} h\right) \\
\leq & \alpha\left(b-\pi_{\mathrm{S}} h\right)+(1-\alpha)\left(b-\pi_{\mathrm{U}} h\right) \\
= & W(0) .
\end{aligned}
$$

Case 2. $b<\pi_{\mathrm{U}} h$. 
For $d \leq \underline{d}$, we have

$$
W(d)=\alpha\left(b-\pi_{\mathrm{S}} h\right)+(1-\alpha) \min \left\{\frac{b-\pi_{\mathrm{U}}\left(1-\varepsilon_{\mathrm{S} \mid \mathrm{U}}\right) d}{\bar{e}}, 1\right\}\left(b-\pi_{\mathrm{U}} h\right),
$$

which is constant in $d$ for $d<(b-\bar{e}) /\left[\pi_{\mathrm{U}}\left(1-\varepsilon_{\mathrm{S} \mid \mathrm{U}}\right)\right]$ and increasing in $d$ for $(b-\bar{e}) /\left[\pi_{\mathrm{U}}\left(1-\varepsilon_{\mathrm{S} \mid \mathrm{U}}\right)\right] \leq \underline{d}<\underline{d}$. Thus, $d^{*} \geq \underline{d}$.

Now consider $d \in[\underline{d}, \bar{d})$. For $d$ in this range,

$$
W(d)=\alpha \frac{b-\pi_{\mathrm{S}} \varepsilon_{\mathrm{U} \mid \mathrm{S}} d}{\bar{e}}\left(b-\pi_{\mathrm{S}} h\right)+(1-\alpha) \frac{b-\pi_{\mathrm{U}}\left(1-\varepsilon_{\mathrm{S} \mid \mathrm{U}}\right) d}{\bar{e}}\left(b-\pi_{\mathrm{U}} h\right) .
$$

By the assumption that $d^{\star}<\bar{d}$, we have that, for all $d \in(\underline{d}, \bar{d})$,

$$
W^{\prime}(d)=(1-\alpha) \frac{\pi_{\mathrm{U}}\left(1-\varepsilon_{\mathrm{S} \mid \mathrm{U}}\right)}{\bar{e}}\left(\pi_{\mathrm{U}} h-b\right)-\alpha \frac{\pi_{\mathrm{S}} \varepsilon_{\mathrm{U} \mid \mathrm{S}}}{\bar{e}}\left(b-\pi_{\mathrm{S}} h\right) \leq 0,
$$

which implies that $d^{*}=\underline{d}$. Q.E.D.

Proof of Proposition 3. By lemma 4, we only need to compare $W(\bar{d})$ and $W(\underline{d})$ to solve for $d^{*}$ :

$$
\begin{aligned}
& W(\bar{d})=\alpha \frac{b-\pi_{\mathrm{S}} \varepsilon_{\mathrm{U} \mid \mathrm{S}} \bar{d}}{\bar{e}}\left(b-\pi_{\mathrm{S}} h\right)+(1-\alpha) \frac{b-c}{\bar{e}}\left(b-c-\pi_{\mathrm{U}}^{L} h\right) ; \\
& W(\underline{d})=\alpha\left(b-\pi_{\mathrm{S}} h\right)+(1-\alpha) \min \left\{\frac{b-\pi_{\mathrm{U}}\left(1-\varepsilon_{\mathrm{S} \mid \mathrm{U}}\right) \underline{d}}{\bar{e}}, 1\right\}\left(b-\pi_{\mathrm{U}} h\right) .
\end{aligned}
$$

From equation (A9), we have that $W(\bar{d})>W(\underline{d})$ if and only if $(1-\alpha) L_{\mathrm{U}}>$ $\alpha G_{\mathrm{S}}$, or $\alpha<L_{\mathrm{U}} /\left(L_{\mathrm{U}}+G_{\mathrm{S}}\right)$, where

$$
G_{\mathrm{S}}=\left[1-\left(\frac{b-\pi_{\mathrm{S}} \varepsilon_{\mathrm{U} \mid \mathrm{S}} \bar{d}}{\bar{e}}\right)\right]\left(b-\pi_{\mathrm{S}} h\right)
$$

and

$$
L_{\mathrm{U}}=\frac{b-c}{\bar{e}}\left(b-c-\pi_{\mathrm{U}}^{L} h\right)-\min \left\{\frac{b-\pi_{\mathrm{U}}\left(1-\varepsilon_{\mathrm{S} \mid \mathrm{U}}\right) \underline{d}}{\bar{e}}, 1\right\}\left(b-\pi_{\mathrm{U}} h\right) .
$$

Q.E.D.

Proof of Proposition 4. Firm behavior when facing fine $f$ is the same as firm behavior when facing negligence damage award $d=2 f$ in the special case in which $\varepsilon_{\mathrm{S} \mid \mathrm{U}}=\varepsilon_{\mathrm{U} \mid \mathrm{S}}=\frac{1}{2}$. Therefore, the problem of choosing $f_{\hat{\theta}}$ to maximize $W_{\hat{\theta}}\left(f_{\hat{\theta}}\right)$ is the same as choosing $d=2 f_{\hat{\theta}}$ to maximize $W(d)$, replacing population proportions $(\alpha, 1-\alpha)$ with proportions $\left(\alpha_{\hat{\theta}}, 1-\alpha_{\hat{\theta}}\right)$. Conditions (22) and (23) then follow from proposition 3 , where we define

$$
G_{\mathrm{S}}^{\mathrm{R}}=\left[1-\left(\frac{b-\pi_{\mathrm{S}} \bar{f}}{\bar{e}}\right)\right]\left(b-\pi_{\mathrm{S}} h\right)
$$


and

$$
L_{\mathrm{U}}^{\mathrm{R}}=\frac{b-c}{\bar{e}}\left(b-c-\pi_{\mathrm{U}}^{L} h\right)-\min \left\{\frac{b-\pi_{\mathrm{U}} \underline{f}}{\bar{e}}, 1\right\}\left(b-\pi_{\mathrm{U}} h\right) .
$$

Q.E.D.

Proof of Proposition 5. From propositions 3 and 4, comparing the performance of regulators to courts boils down to comparing

$$
\max _{\left(\hat{S}_{\hat{S}}, f \hat{\mathrm{U}}\right) \in\{(f, f),(f, \bar{f}),(\bar{f}, \bar{f})\}} W\left(f_{\hat{S}}, f_{\hat{\mathrm{U}}}\right)
$$

to

$$
\max _{d \in\{d, \bar{d}\}} W(d)
$$

where regulators perform better than courts if and only if expression (A14) exceeds expression (A15).

The problem can be simplified since $W(\underline{f}, \underline{f}) \leq W(\underline{d})$ and $W(\bar{f}, \bar{f}) \leq W(\bar{d})$. To see this, note that

$$
W(\underline{f}, \underline{f})=\alpha\left(b-\pi_{\mathrm{S}} h\right)+(1-\alpha) \min \left\{1, \frac{b-\pi_{\mathrm{U}} \underline{f}}{\bar{e}}\right\}\left(b-\pi_{\mathrm{U}} h\right)
$$

is less than or equal to

$$
W(\underline{d})=\alpha\left(b-\pi_{\mathrm{S}} h\right)+(1-\alpha) \min \left\{1, \frac{b-\pi_{\mathrm{U}}\left(1-\varepsilon_{\mathrm{S} \mid \mathrm{U}}\right) \underline{d}}{\bar{e}}\right\}\left(b-\pi_{\mathrm{U}} h\right)
$$

since $\pi_{\mathrm{U}}\left(1-\varepsilon_{\mathrm{S} \mid \mathrm{U}}\right) \underline{d} \geq \pi_{\mathrm{U}} f$ when $b<\pi_{\mathrm{U}} h$, and

$$
W(\bar{f}, \bar{f})=\alpha\left(\frac{b-\pi_{\mathrm{S}} \bar{f}}{\bar{e}}\right)\left(b-\pi_{\mathrm{S}} h\right)+(1-\alpha) \frac{b-c}{\bar{e}}\left(b-c-\pi_{\mathrm{U}}^{L} h\right)
$$

is less than or equal to

$$
W(\bar{d})=\alpha\left(\frac{b-\pi_{\mathrm{S}} \varepsilon_{\mathrm{U} \mid \mathrm{S}} \bar{d}}{\bar{e}}\right)\left(b-\pi_{\mathrm{S}} h\right)+(1-\alpha) \frac{b-c}{\bar{e}}\left(b-c-\pi_{\mathrm{U}}^{L} h\right)
$$

since $\pi_{\mathrm{S}} \varepsilon_{\mathrm{U} \mid \mathrm{S}} \bar{d} \leq \pi_{\mathrm{S}} \bar{f}$.

As a result, regulators perform (strictly) better than courts if and only if $W(\underline{f}, \bar{f})>\max _{d \in\{\underline{d}, \bar{d}\}} W(d)$. There are two cases to consider.

Case 1. $\alpha<L_{\mathrm{U}} /\left(L_{\mathrm{U}}+G_{\mathrm{S}}\right)$.

In this case, $\max _{d \in\{\underline{d}, \bar{d}\}} W(d)=W(\bar{d})$ by proposition 3, so regulators perform better than courts if and only if $W(f, \bar{f})>W(\bar{d})$. Algebraic manipulations reveal that this inequality holds if and only if $\alpha \tilde{G}_{\mathrm{S}}>(1-\alpha) \tilde{L}_{\mathrm{U}}>0$ or if and only if $\tilde{G}_{\mathrm{S}}>0$ and $\alpha>\tilde{L}_{\mathrm{U}} /\left(\tilde{L}_{\mathrm{U}}+\tilde{G}_{\mathrm{S}}\right)$, where 


$$
\tilde{G}_{\mathrm{S}}=\left[\frac{\left(1-\delta_{\mathrm{U} \mid \mathrm{S}}\right)(\bar{e}-b)+\pi_{\mathrm{S}} \varepsilon_{\mathrm{U} \mid \mathrm{S}} \bar{d}-\pi_{\mathrm{S}} \delta_{\mathrm{U} \mid \mathrm{S}} \bar{f}}{\bar{e}}\right]\left(b-\pi_{\mathrm{S}} h\right)
$$

and

$$
\tilde{L}_{\mathrm{U}}=\delta_{\mathrm{S} \mid \mathrm{U}}\left[\frac{b-c}{\bar{e}}\left(b-c-\pi_{\mathrm{U}}^{L} h\right)-\min \left\{\frac{b-\pi_{\mathrm{U}} \underline{f}}{\bar{e}}, 1\right\}\left(b-\pi_{\mathrm{U}} h\right)\right] .
$$

Case 2. $\alpha \geq L_{\mathrm{U}} /\left(L_{\mathrm{U}}+G_{\mathrm{S}}\right)$.

In this case, $\max _{d \in\{d, \bar{d}\}} W(d)=W(\underline{d})$ by proposition 3, so regulators perform better than courts if and only if $W(f, f)>W(\underline{d})$. Algebraic manipulations reveal that this inequality holds if and only if $(1-\alpha) \tilde{G}_{U}>\alpha \tilde{L}_{S}>0$ or if and only if $\tilde{G}_{\mathrm{U}}>0$ and $\alpha<\tilde{G}_{\mathrm{U}} /\left(\tilde{G}_{\mathrm{U}}+\tilde{L}_{\mathrm{S}}\right)$, where

$$
\begin{gathered}
\tilde{G}_{\mathrm{U}}=\left(1-\delta_{\mathrm{S} \mid \mathrm{U}}\right) \frac{b-c}{\bar{e}}\left(b-c-\pi_{\mathrm{U}}^{L} h\right) \\
-\left[\min \left\{1, \frac{b-\pi_{\mathrm{U}}\left(1-\varepsilon_{\mathrm{S} \mid \mathrm{U}}\right) \underline{d}}{\bar{e}}\right\}-\delta_{\mathrm{S} \mid \mathrm{U}} \min \left\{1, \frac{b-\pi_{\mathrm{U}} f}{\bar{e}}\right\}\right]\left(b-\pi_{\mathrm{U}} h\right)
\end{gathered}
$$

and

$$
\tilde{L}_{\mathrm{S}}=\delta_{\mathrm{U} \mid \mathrm{S}}\left[1-\frac{b-\pi_{\mathrm{S}} \bar{f}}{\bar{e}}\right]\left(b-\pi_{\mathrm{S}} h\right)
$$

Q.E.D.

Proof of Proposition 6. The problem of finding $d_{\hat{\theta}}$ to maximize $W_{\hat{\theta}}\left(d_{\hat{\theta}}\right)$ is the same as the problem of finding $d$ to maximize $W(d)$, replacing population proportions $\alpha$ and $1-\alpha$ with proportions $\alpha_{\hat{\theta}}$ and $1-\alpha_{\hat{\theta}}$. The result then follows from proposition 3, where $L_{\mathrm{U}}$ and $G_{\mathrm{S}}$ are defined as in the proof of that proposition. Q.E.D.

\section{References}

$\rightarrow$ Becker, Gary. 1968. Crime and Punishment: An Economic Approach. Journal of Political Economy 76:169-217.

$\rightarrow$ Becker, Gary, and George Stigler. 1974. Law Enforcement, Malfeasance, and Compensation of Enforcers. Journal of Legal Studies 3:1-18.

Calabresi, Guido. 1970. The Cost of Accidents. New Haven, Conn.: Yale University Press.

$\rightarrow$ Calfee, John E., and Richard Craswell. 1984. Some Effects of Uncertainty on Compliance with Legal Standards. Virginia Law Review 70:965-1003.

Chetty, Raj. 2011. Bounds on Elasticities with Optimization Frictions: A Synthesis of Micro and Macro Evidence on Labor Supply. Working Paper No. 15616. National Bureau of Economic Research, Cambridge, Mass.

$\rightarrow$ Coase, R. H. 1960. The Problem of Social Cost. Journal of Law and Economics 3:1-44. 
$\rightarrow$ Craswell, Richard, and John E. Calfee. 1986. Deterrence and Uncertain Legal Standards. Journal of Law, Economics, and Organization 2:279-303.

$\rightarrow$ Curfman, Gregory, Stephen Morrissey, and Jeffrey Drazen. 2008. Why Doctors Should Worry about Preemption. New England Journal of Medicine 359:1-3.

$\rightarrow$ Emons, Winand, and Joel Sobel. 1991. On the Effectiveness of Liability Rules When Agents Are Not Identical. Review of Economic Studies 58:375-90.

$\rightarrow$ Gennaioli, Nicola, and Andrei Shleifer. 2008. Judicial Fact Discretion. Journal of Legal Studies 37:1-35.

$\rightarrow$ Glaeser, Edward, Simon Johnson, and Andrei Shleifer. 2001. Coase versus the Coasians. Quarterly Journal of Economics 116:853-899.

$\rightarrow$ Glaeser, Edward, and Andrei Shleifer. 2003. The Rise of the Regulatory State. Journal of Economic Literature 41:401-25.

$\rightarrow$ Glantz, Leonard, and George Annas. 2008. The FDA, Preemption, and the Supreme Court. New England Journal of Medicine 358:1883-85.

$\rightarrow$ Immordino, Giovanni, Marco Pagano, and Michele Polo. 2011. Incentives to Innovate and Social Harm: Laissez-faire, Authorization or Penalties? Journal of Public Economics 95:864-76.

$\rightarrow$ Kaplow, Louis, and Steven Shavell. 1996. Accuracy in the Assessment of Damages. Journal of Law and Economics 39:191-210.

Kessler, David, and David Vladeck. 2008. A Critical Examination of the FDA's Efforts to Preempt Failure-to-Warn Claims. Georgetown Law Journal 96:461-72.

$\rightarrow$ Kolstad, Charles, Thomas Ulen, and Gary Johnson. 1990. Ex Post Liability for Harm vs. Ex Ante Safety Regulation: Substitutes or Complements? American Economic Review 80:888-901.

Laffont, Jean-Jacques, and Jean Tirole. 1993. A Theory of Incentives in Procurement and Regulation. Cambridge, Mass.: MIT Press, 1993.

Landis, James. 1938. The Administrative Process. Westport, Conn.: Greenwood Press.

$\rightarrow$ Mankiw, N. Gregory, and Michael D. Whinston. 1986. Free Entry and Social Inefficiency. RAND Journal of Economics 17:48-58.

Philipson, Tomas, Eric Sun, and Dana Goldman. 2009. The Effects of Product Liability Exemption in the Presence of the FDA. Working Paper No. 15603. National Bureau of Economic Research, Cambridge, Mass.

$\rightarrow$ Png, Ivan. 1986. Optimal Subsidies and Damages in the Presence of Judicial Error. International Review of Law and Economics 6:101-5.

$\rightarrow$ Polinsky, A. Mitchell. 1980. Strict Liability vs. Negligence in a Market Setting. American Economic Review 70:363-67.

$\rightarrow$ Polinsky, A. Mitchell, and Steven Shavell. 2000. The Economic Theory of Public Enforcement of Law. Journal of Economic Literature 38:45-76.

$\rightarrow$ Posner, Richard. 1972. A Theory of Negligence. Journal of Legal Studies 1:29-96.

$\rightarrow-$ 1973. Strict Liability: A Comment. Journal of Legal Studies 2:205-21.

$\rightarrow$ Schwartz, Alan. 2000. Statutory Interpretation, Capture, and Tort Law: The Regulatory Compliance Defense. American Law and Economics Review 2:1-57.

$\rightarrow$ Shavell, Steven. 1980. Strict Liability versus Negligence. Journal of Legal Studies 9:1-25.

$\rightarrow \longrightarrow$. 1984a. Liability for Harm versus Regulation of Safety. Journal of Legal Studies 13:357-74.

$\rightarrow-1984$ b. A Model of the Optimal Use of Liability and Safety Regulation. RAND Journal of Economics 15:271-80. 

36:255-87.

1993. The Optimal Structure of Law Enforcement. Journal of Law and Economics

. 2004. Foundations of Economic Analysis of Law. Cambridge, Mass.: Belknap Press.

$\rightarrow$ Spence, Michael. 1977. Consumer Misperceptions, Product Failure and Producer Liability. Review of Economic Studies 44:561-72.

$\rightarrow$ Summers, John. 1983. The Case of the Disappearing Defendant: An Economic Analysis. University of Pennsylvania Law Review 132:145-85.

$\rightarrow$ Viscusi, Kip. 1991. Product and Occupational Liability. Journal of Economic Perspectives 5:71-91.

$\rightarrow$ Viscusi, Kip, and Michael Moore. 1993. Product Liability, Research and Development, and Innovation. Journal of Political Economy 101:161-84. 